\section{An Evaluation of Prevalence of Low Quality of Medicines in Saudi Arabia and Factors Associated an Analytical Comparative Study}

\section{Abstract}

From the beginning, human beings have looked for quality in all criteria of their lives. Quality is a universal concept, both sensible and uncomplicated, but its definition is usually subjective. Medicine has been fundamental throughout history in the management of diseases and prevention of illnesses. Over the period of time, the surveillance by states, general and private professionals, and customers has confirmed that those drugs are effective and safe.

Keywords: Drugs; Medicine; Disease

\section{Abdulaziz Alhedethe*, Khaled Alhudaithy and Mire Zloh}

Department of Pharmacy, School of Life and Medical Science, University of Hertfordshire, UK

\section{*Corresponding author: Abdulaziz Alhedethe \\ abdulazizalhedethe@gmail.com \\ Department of Pharmacy, School of Life and Medical Science, University of Hertfordshire, UK.}

Tel: +91-9451-019049

\section{Introduction}

\section{Background}

From the beginning, human beings have looked for quality in all criteria of their lives. Quality is a universal concept, both sensible and uncomplicated, but its definition is usually subjective. Medicine has been fundamental throughout history in the management of diseases and prevention of illnesses. Over the period of time, the surveillance by states, general and private professionals, and customers has confirmed that those drugs are effective and safe.

Quality is built into a medicine during its design, improving, and making. Producers are firstly responsible for the quality of the drugs they make by following the principle of good manufacturing practices (GMP). After a product comes out of the factory, distributors, purchasing agencies (purchasers), dispensers, and consumers are responsible for maintaining the quality of the product through suitable storage, transfer, distribution, dispensing, and consumption. The producers should take responsibility for the quality of the medicines to confirm that they are fit for their desired consumption, comply with the standards of the marketing authorisation, and do not put patients in danger through inappropriate efficacy, safety or quality. The realisation of this quality goal is the responsibility of Senior Management and requires the sharing and discipline of workers in many different sections and at all levels within the institute, the institute providers, and the dispensers [1-5].

\section{Definition of medicine terminology}

Medication, drug, pharmaceutical drug and medicine are a set of
Citation: Alhedethe A, Alhudaithy K, Zloh AM (2017) An Evaluation of Prevalence of Low Quality of Medicines in Saudi Arabia and Factors Associated an Analytical Comparative Study. Arch Chem Res. Vol.2 No.1:1

terms symbolising a single meaning, which have many definitions from different sources. Definitions of pharmaceutical quality have been evolving for years. The International Conference on Harmonization of Technical Requirements for Registration of Pharmaceuticals for Human Use (ICH) has defined drug quality, simply, as "the ability of a product to satisfy stated needs, including purity, identity and strength, without undesired adverse effects". The definition of medicine according to Pharma's journal is "any chemical substance formulated or compounded as single active ingredient or in combination of other pharmacologically active compounds". Another definition of medicines is "chemical agents which can be used for prevention, alleviation, cure or diagnosis of diseases. Therefore, in contrast to chemical agents, drugs are intended as beneficial substances for treating diseases and maintaining health". In contrast, In Europe, the term is "medicinal product", and it is defined by European law as "any substance or combination of substances presented as having properties for treating or preventing disease in human beings"; or "any substance or combination of substances which may be used in or administered to human beings either with a view to correcting, restoring or modifying physiological effects by exerting immunological, pharmacological or metabolic action, or to making a medical investigation". In US law, a "drug" is "a substance intended for use in the diagnosis, 
mitigation, cure, treatment, and prevention of illness" The definition of the WHO is as follows: "Pharmaceutical products - more commonly known as medicines or drugs are a fundamental component of both modern and traditional medicine. It is essential that such products are effective, safe, and of good quality, and are used and prescribed rationally". Quality concerns how something reaches the best situation. The product can be fit for its target if its quality is high. If the quality is less than the standard, the product may break easily or not work correctly. ISO defines quality as "the totality of features and characteristics of a product or service that bear its ability to satisfy stated or implied needs" In manufacturing, quality is the degree of uniqueness or a case of being free from flaws, deficiency and significant differences. It's achieved by strong and harmonising adherence to certain levels that confirm uniformity of a product in order to accept specific customer requirements [6-15].

\section{Key players for high quality of medicines}

National government leaders and policymakers are responsible for national drug policies and procedures that include access, quality assurance, proper consumption, and other estimations. Many countries have met remarkable success through establishing and supporting quality assurance programmes; nevertheless, a few low- and middle-income countries include quality control and good manufacturing practices (GMP) in their national drug policies. For example, experience in the United States, Australia, and Canada has shown that appropriate regulations and their implementation result in minimal low pharmaceutical quality and maximal public satisfaction in the quality of the medicines. National medicine regulatory authorities are the key activities of national medicine regulatory authorities are to assure the quality, safety and efficacy of locally manufactured pharmaceutical products and imported products, registering pharmaceutical products, and licensing medicine institutions. Furthermore, they monitor and inspect manufacturing, dispensing, and retail buildings for differences with respective practice and guidelines, including (GMP), storage and distribution, and fully dispensing operations, as well as ensure safety of food and drugs for man and animal, and the safety of chemical and biological substances as well as electronic products. Moreover, The Saudi Food and Drug Authority was established in 2003. The main purpose of the SFDA's establishment is to regulate, manage, and control food, pharmaceutical products, medical devices, as well as to set compulsory standard specifications. The main objectives of SFDA can be outlined as follows:

- Observe the safety, security, and effectiveness of medicines.

- Ensure accuracy and safety of medical and diagnostic devices.

- Control and supervise licensing measures for food, pharmaceutical products and medical device manufacturers.

- Disseminate and exchange information with local and international scientific and authorised organisations, and set up a database for food and medicines (SFDA, 2006).
Producers of medicine products are the pharmaceutical manufacturers have the main responsibility to ensure the safety, liability and quality of the products. In addition, Quality assurance is defined by the WHO as "a wide-ranging concept covering all matters that individually or collectively influence the quality of a product". It is the total of the arrangements made with the objective of ensuring that medicine products are of the quality required for their proposed consumption. Quality assurance therefore incorporates GMP and other issues, including those outside the scope of this guide, such as product creation and improvement. Also, Pharmaceutical quality control is the process concerned with medicine sampling, standardisation, and examination, and with the institutes' release methods that assure that the necessary tests are done and that the materials are not approved for use - products released for either sale or supply - until their quality has been tested correctly. Besides, Good manufacturing practices for pharmaceutical products (GMP) is that part of quality management which ensures that products are appropriately produced and monitored according to the quality specifications adequate for their intended use and as wanted by the marketing authorisation, clinical trial approving or product standardisation. GMP is concerned with both production and quality control (QC). GMP is targeted firstly at organising and reducing the risks inherent in medicine manufacturing to confirm the quality, safety and usefulness of products. Medicine prescribers and dispensers Healthcare experts' missions who prescribe drugs, as well as dispensers who dispense medicines, are according to nationally or internationally accepted standards, as follows:

Furthermore, Informing patients about the proper use of medicines; advising patients to purchase medicines only from licensed retailers; telling patients to report any adverse drug reactions from taking the medicines; reporting any adverse drug reactions to the appropriate authorities; ensuring that they purchase, stock, and dispense only high-quality medicines; ensuring a safe, clean, and secure dispensing environment; and receiving, verifying, and understanding prescriptions.

Patients, consumers, and patient advocacy groups persons who use medicines must also take responsibility for their own health by: purchasing or obtaining medicines only from outlets or health facilities that are properly authorised or licensed to dispense medicines; examining physically and visually the medicines they purchase or receive to ensure that they have received the correct product in the right strength with a current expiry date; ensuring that medicines bear appropriate labelling and instructions regarding their use; and Following the advice provided by dispensers and physicians, as well as instructions on labels $[16,17]$.

\section{Poor Quality of Medicines}

\section{Historical overview}

Globalisation of the pharmaceutical industry has the potential to rapidly produce poor quality of medicines worldwide before adequate detection and intervention are possible. Despite the logical implication that poor-quality medicines will reduce 
the effectiveness of therapy and encourage drug resistance, there has been relatively little apparent interest in the quality of medicines used to treat common life-threatening diseases. Accurate definitions are important not only as a framework for governments to develop their legal instruments, but also from the perspective of developing appropriate analysis methods with the necessary ability to distinguish different types of poor quality of drugs. In contrast, in many reports, it is unclear if poor quality of medicines means counterfeit or substandard, but it is important that they are correctly classified because they have different origins and different solutions. In adequate enforcement, lenient penalties, corruption, unregistered medicines, and ignorance of poor-quality medicines among the public and health workers exacerbate the situations [18-25].

\section{Types of poor-quality medicines}

Poor-quality medicines can be classified into three different main types: substandard, counterfeit and degraded. Substandard medicines "are genuine medicines produced by legitimate manufacturers that do not meet the quality specifications that the producer says they meet. For example, they may contain less (or more) active ingredient than written on the package. This may not be an intention to cheat, but may be due to problems with the manufacturing process. Moreover, Counterfeit medicines are deliberately and fraudulently mislabelled with respect to identity and / or source. Counterfeiting may include products with the correct ingredients or with the wrong ingredients, without active ingredients, with insufficient active ingredients or with fake packaging". Degraded medicines may result from exposure of good-quality medicines to light, heat, and humidity. It can be difficult to distinguish degraded medicines from those that left the factory as substandard, but the distinction is important as the causes and remedies are different $[26,27]$.

\section{Prevalence of poor quality of medicines}

The accurate range of the poor-quality medicines is unknown but can occur worldwide (Figure 1). Concerning the evidence suggesting that substandard, counterfeit, or degraded medicines are major problems of global importance, there are few reliable data describing their epidemiology. Therefore, a few published analyses by agents and reports by international organisations, such as the WHO, have collected information from individual studies or a range of countries to try to gain an overview of the prevalence of poor-quality medicines in developing countries (Figure 2). In other hand, the experts estimate that only 5-15\% of the 191 member states of the WHO report cases of counterfeit medicines. India has been stated to be the largest producer of counterfeit medicines, accounting for about 35\% of counterfeit medicines distributed worldwide. Nigeria is thought to account for about 23\% and Pakistan 13.3\%, Many data have been interpreted uncritically, while some are inaccurate and do not allow accurate generalisations about the epidemiology of poor-quality medicines. In other hand, a lot of the information on the medicines' quality is published in grey literature such as in Internet articles and newspapers instead of in professional literature. Thirty-eight quantitative studies conducted in various African regions studies conducted to assess the proportion of collected samples

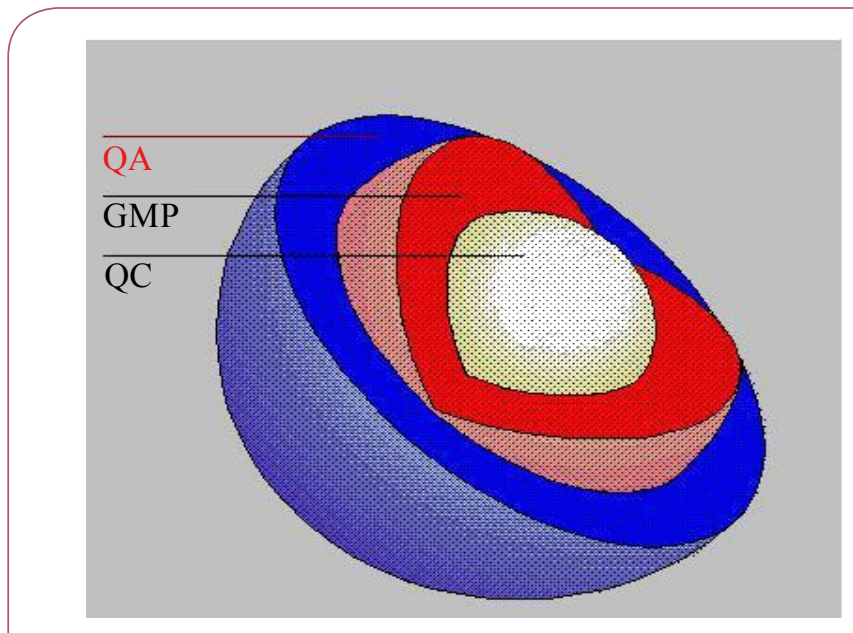

Figure 1 Diagram of QC, GMP, and QA.

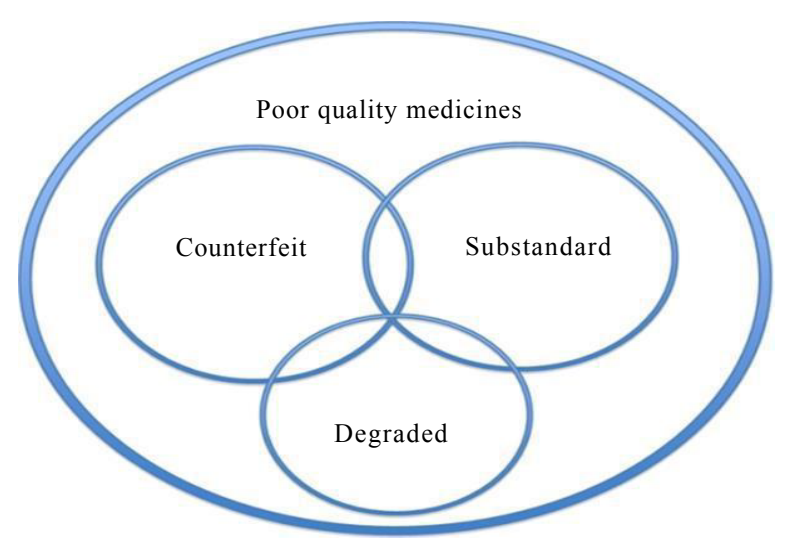

Figure 2 Poor poor-quality frame.

which did not meet pharmaceuticals standards - in order to determine the frequency of poor-quality medicines in such areas were identified. None of the studies identified obviously featured between substandard and counterfeit medicines. Studies aimed at evaluating the prevalence of low-quality medicines, where obtainable, are often limited to a few drug classes and test drugs for a narrow group of diseases such as antibiotics and antimalarial. The majority of the studies conducted in developing countries in order to determine the extent of poor-quality medicines show that about half of the medicines examined were substandard. From the results of these studies it is not easy to exactly confirm the actual extent of poor-quality medicines or to compare the results in different countries due to the limited sample size and sampling of specific drug classes in most of the studies identifying nonuniformity in the methods employed in these studies (Figure 3). Furthermore, the scientific report confirmed the falsified or substandard medicines in many pharmacy therapeutic classes, with antibiotics and anti-parasitic medicines appearing far more likely to be counterfeits than other medicines. In other context, the problem of patient exposure to poor-quality medicines is not limited to developing countries; IMPACT expected that the spread of counterfeit medicines would be less than $1 \%$ of sales in most developed countries with acceptable regulatory systems 
and pharmaceutical market control. A search of the UK's MHRA website revealed that between December 2005 and October 2012, 211 drug alerts were delivered, including 22 Class 1 (critical) alerts for problems such as counterfeited medicines, packaging issues, inappropriate medicine quantities, and adulteration Between March 2011 and November 2012, approximately 40 companyled recalls were also issued for problems.Such as contamination, inadequate labelling and stability or packaging concerns. The country of origin of the medicines concerned was not specified. Counterfeits of most commonly used essential medicines have been described, with a recent review describing 206 cases of counterfeit anti-infective from 38 countries. Furthermore, of 771 reports of counterfeit medicines received by the WHO from 1982 to $1999,48 \%$ were from the Western Pacific region, with most being labelled as anti-infective. Substandard products have also been with us since medicines were first compounded. They are an inevitable consequence of inadequate local regulation of the pharmaceutical industry and the lack of good manufacturing practices (GMP) in facilities in many developing countries. Substandard medicines are sold via the Internet, thus potentially touching a wide patient population. The WHO has estimated that over $50 \%$ of drugs bought via the Internet are falsified. However, an analysis of selected medicines bought from a wide range of website pharmacies found that, with the exception of Viagra ${ }^{\circledR}$, the medicines met quality standards.

According to a recent survey done by African researchers in six African countries, one third of antimalarial medicines did not contain active ingredients, in 2012 in Pakistan, more than 120 people died, and hundreds more suffered adverse reactions after taking a contaminated heart medicine [28-35].

Counterfeit and substandard drugs are prevalent and spread worldwide, but developing countries are the worst influenced. Counterfeiting is generally perceived by society as a fine crime, and recognised by criminals as having a low risk of suing with light punishment, proportional to the large income to be made.
The factors which participate in the spread of fake medicines include a lack of adequate legislation, poor regulatory authorities, weak enforcement, corruption, and the transparent affectation of the wrongful drug manufacturing industry. In October 2008, the director of a pharmaceutical manufacturing company, Abdullah Al-Abdelgader, estimated that around 30-40 percent of the medicines sold at pharmacies and hospitals in the Kingdom were counterfeit. In 2009, it was estimated that roughly 14 percent of the medicines sold in the Kingdom were fake. In 2009, several raids led Saudi police to seize nearly 4 million anti-depressant treatments and arrest several drug traffickers. Authorities shut down an unlicensed clinic for weight loss pills, and seized a large quantity of fake medications during the raid. According to the European Commission's 2006 report, 31 percent of fake medicines imported into the EU originated from the United Arab Emirates. One media report from 2008 says that "inspectors from the Department of Economic Development seized huge quantities of herbal medicine sold by shops claiming to treat diabetes. The authorities sent samples of the medication for analysis and the Medical District reported that it never issued any approval for this particular herbal medication to circulate in the emirate". Also, in 2007, Dubai customs inspectors infiltrated a complex counterfeiting supply chain, which ran through China, Hong Kong, the United Arab Emirates, Britain, and the Bahamas. These counterfeiters marketed the drugs to American consumers via an online pharmacy purportedly operating out of Canada. Customs officials in the UAE confiscated roughly five million counterfeit sexual stimulant tablets and sedative drugs, which were worth more than USD 5.4 million, from a company warehouse operating in the Jebel Ali Free Zone Area (JAFZA). Other seizures included counterfeit cholesterol-lowering medicine and antibiotics. Dubai customs has destroyed illicit drugs under controlled environmental conditions. Dubai is particularly attractive to counterfeiters because of its strategic position. Located in the Persian Gulf, Dubai lies on a major trading route which connects Asia, Europe and Africa by both land and sea. Qatar has recently

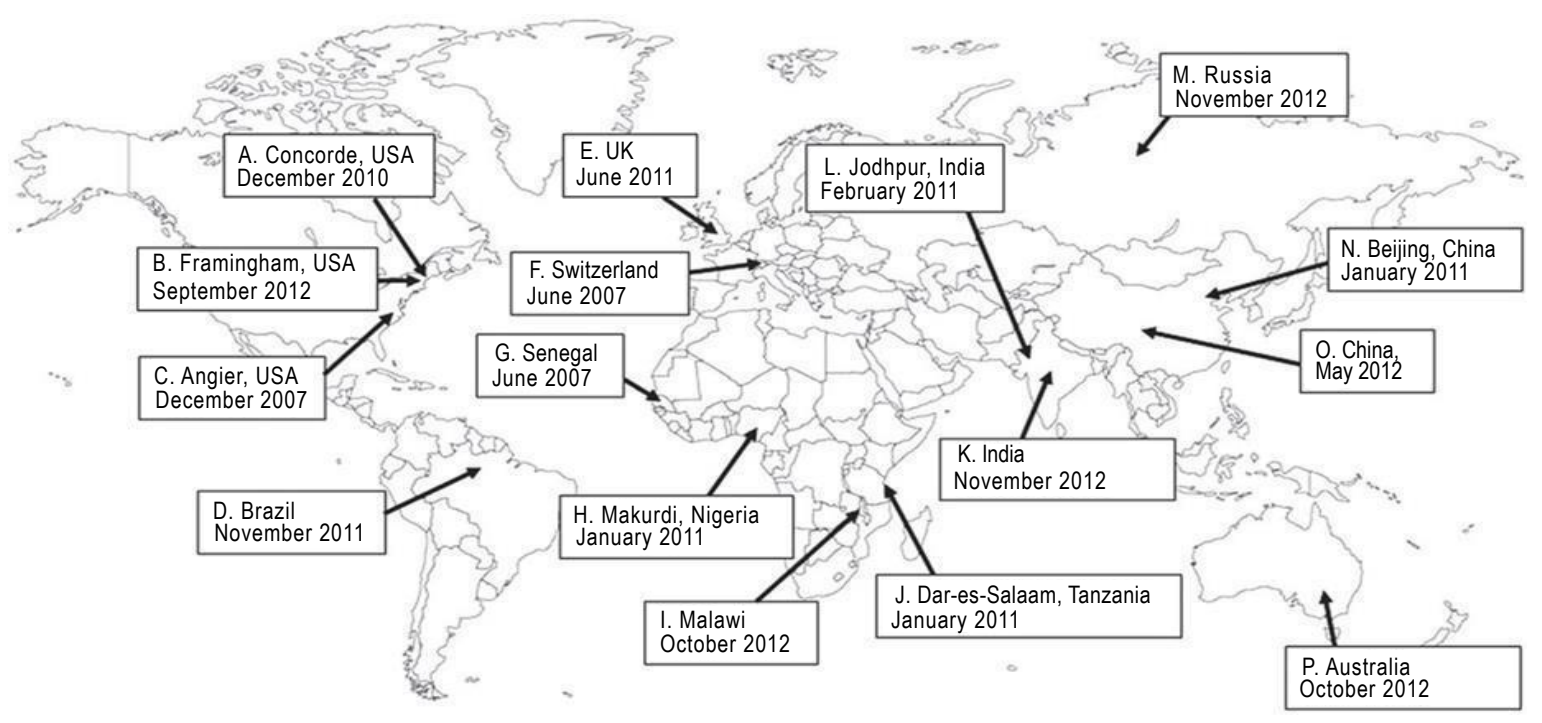

Figure 3 Prevalence image of poor quality drug. 
faced an influx of fake diet pills from neighbouring countries. Despite strict warnings from the Drugs Control Department at the Supreme Council of Health, these pills continue to slip into the country. Most appear to have originated in China, and many contain a dangerous chemical, not listed in the ingredients, which is internationally banned because of its dangerous side effects [36,37]

\section{Impact of poor quality of medicines}

Considering the large scale of world medicine markets and the happening of possible deadly diseases, any level of low quality of medicines is inadmissible. The influence of low-quality drugs is most obviously evident if they contain fatal, erroneous active ingredients. Moreover, patients could suffer side effects of unexpected ingredients, e.g. counterfeit artesunate tablets containing artemisinin, chloramphenicol, paracetamol, and metamizole. Some substandard medicines consist of more active components than declared and for anti-infective with a narrow therapeutic index, this could extend the spread of side effects. Erroneous reports of drug resistance to malaria have resulted from the use of poor-quality anti-malarial medicines. Some of the concerned impacts of poor-quality medicines are the loss of confidence in health systems and health workers, and the loss of financial resources for patients and their families. This may affect the local and global pharmaceutical markets in the long term. Identification of poor quality medicines is not specific in certain area of the world; the problem of poor quality medicines is a global issue affecting many classes of drugs. The most reported low quality medicines cases were failure to comply with the standard of active pharmaceutical ingredients. Also failure of disintegration and dissolution tests has been reported. There are other cases of poor quality medicines has been observed including fake packaging, no manufacturer address or no expiry dates and no origin country stated [38-40].

\section{Health Care System in Saudi Arabia}

The health care system is concerned with the investigation, management, and prevention of disease, illness, infections, and other physical and psychological impairments in human lives. Health care is delivered by specialists in allied health, dentistry, midwifery (obstetrics), nursing, medicines,, pharmacy, and other health careers. It refers to the service done in providing primary, secondary, and tertiary care, The Kingdom of Saudi Arabia is one of the largest countries in the Middle East at 2.24 million $\mathrm{km}^{2}$. The kingdom of Saudi Arabia government has given high priority to the improvement of health and medical services at all levels:, primary, secondary, and tertiary., as a consequence, in recent decades the health of Saudi Arabian citizens has greatly developed, and the heath health awareness and education for a the majority of people has have been observed. Despite improvements in health care systems across the Saudi Arabia, the health care system face faces some challenges, such as limited financial resources, changing the pattern of diseases, highly high demand 0 resulting from free services, absence of national crisis controlling policy, and shortage of Saudi health professionals, and underutilization underutilisation of potential of electronic health strategies. On the other hand, the ministry of health (MOH) in Saudi Arabia, Arabia has introduces introduced many reforms to its services, and address addressed challenges to achieve continuous improvement of the Saudi health care system and to coordinate with other government organizations organisations to implement and ensure the access to new health care strategies.

\section{Pharmaceutical Market in Saudi Arabia}

The Pharmaceutical market in the Saudi Arabia has witnessed considerable progress over the years on the back of favourable demographic and economic factors, alongside strong government support for healthcare. The Total market size in Saudi Arabia and gulf countries was estimated at US\$ 8.5 billion in 2012, compared to US\$ 7.7 billion in the previous year 1 . It accounts for less than $1 \%$ of the global pharmaceutical sector, which was valued at US\$ 955.5 billion in 2012 (Figure 4). Given the sizeable population base and relatively active domestic pharmaceutical manufacturing segment, Saudi Arabia was the largest market, contributing $59.4 \%$ to the Gulf's overall pharmaceutical industry size in 2012.

The total Saudi pharmaceutical market in 2012 was the highest in gulf council countries with $\$ 5.1$ billion, while the Bahrain pharmaceuticalmarketiswasthelowestwith\$260million(Figure5). In other hand, a community pharmacy is a healthcare facility that is able to provide pharmaceutical services to people in a local area or community. A community pharmacy dispenses medicine and typically involves a registered pharmacist with the education, skills, and competence to deliver professional services to the community. The community pharmacy in Saudi Arabia, not like unlike the community pharmacies of other places, is mainly a commercial venture, with the community pharmacist making limited clinical services in the dispensing of drugs. Despite Nevertheless, a community pharmacist can play an important role in patient advising and should be able to give basic drug information in terms of accurate medicines medicine consumption, administration, dosage level, side effects, storage, and drug-food and drug-drug interactions While, a number of studies have been shown on different aspects of pharmacy practice in both hospitals and private pharmacies in the Kingdom of Saudi Arabia. None of these, however, give a comprehensive image of this important field of health care. Moreover, they fail to provide detailed data of on the range of qualified services, particularly the counselling activities and the period spent in providing them. Similarly, a few trials have been focused to on evaluate evaluating the attitude of the practicing practising

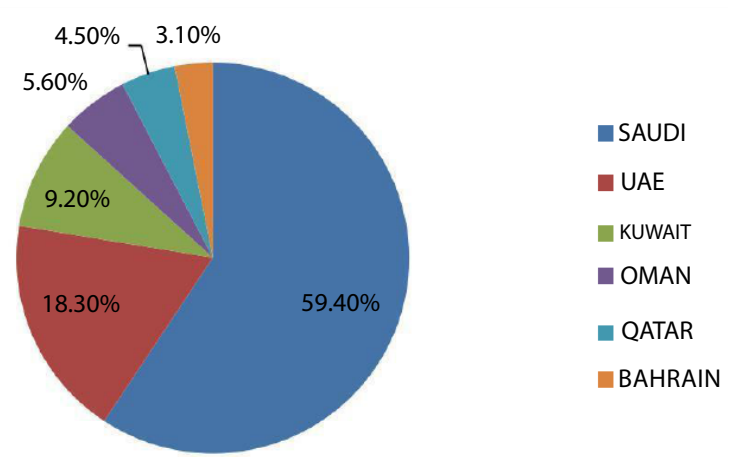

Figure 4 Percentage of pharmaceutical markets in GCC. 


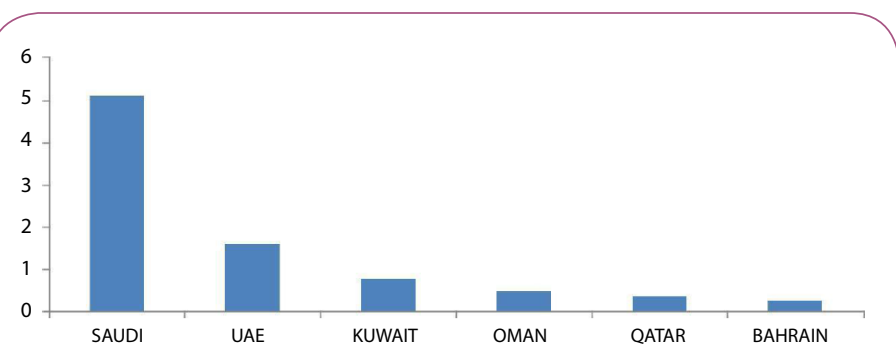

Figure 5 Number Amount of pharmaceutical expenditure in GCC.

pharmacist to towards his profession, and thereby identify identifying the areas of development.

On other hand, pharmacists have been known generally as important healthcare experts, especially with regard to the promotion of rational use and safe safety of drugs. Community pharmacists today are involved in a wide variety of specialized specialised activities, which might be considered as patient care that improves medication therapy and promotes health wellness, and disease prevention. Also, they can act as an important source of providing professional, valid medicines medicine information and should be able to advice regarding the appropriate, pure, safe, and cost-effective usage of drugs.

Community pharmacists have massive responsibilities to optimize optimise medication consumption and participate to in the health results for individuals in their society. To reach this aim, they must have outstanding medication knowledge and should be well rounded in all characteristics of pharmaceutical care. Community pharmacists are the most available health care experts to the general population. In addition to their significant role of dispensing drugs and manage managing minor illnesses, community pharmacists are considered as an important source of drug information for the patients. For these reasons, community pharmacists should have sufficient medicines medicine knowledge to improve therapy for the patients [41-50].

\section{Quality of Medicines in Saudi Arabia}

In Saudi Arabia, official reports on substandard medicines are limited. The predominant source of information appears to be newspaper articles, similar to many countries. In 2003, The Saudi Food and Drug Authority was established. Its main objectives include licensing, inspection and surveillance of manufacturers, monitoring and controlling the quality of medicines in the market, and providing independent information of medicines to professionals and the public WHO estimates that $30 \%$ of countries around the world do not have any medicine control and regulations. Indeed, strengthening drug and health regulatory authorities, producing relatively cheap medicine preparations, and enhancing the quality of products are the key factors in improving the quality of pharmaceutical products. On the other hand, as well as for critical estimation of prevalence of poor quality of drugs, there is a serious need for data of a sufficient sample size with a random sampling design. Such data are essential to evaluate their effectiveness, take appropriate interventions, and follow the change out of times. The Saudi FDA has issued some warnings regarding counterfeit medical products and pharmaceuticals in the past. In 2011, a warning about one batch of the oral antibiotic Augmentin $1 \mathrm{~g}$ was released, which was found to contain the wrong active ingredient following analysis in the SFDA laboratories, Moreover, warnings about counterfeit medical products such as aerosol chamber devices and counterfeit herbal and cosmetic agents were also issued. Pharmaceutical companies in Saudi Arabia estimate that 30$40 \%$ of circulating medicines in pharmacies and hospitals in the country are counterfeit. In contrast, the SFDA insists that is only $0.5 \%$ of medicines in the country are counterfeit. Additionally, there has been no reported prevalence of the level of substandard medicines in the country. The recent growing public concerns of substandard medicines might have triggered the local councils to recommend amendments in the country's pharmaceutical laws, to increase sentences and penalties for offenders.

Additionally, the data on the quality of medicines in Saudi Arabia and Arab countries are very limited. One study reported substandard amoxicillin in four Arab countries. In that study, the content of amoxicillin in capsules and suspensions was investigated, although the number of samples collected from each country and the methodology of sample collection were not specified in detail. However, the authors concluded that the prevalence of substandard amoxicillin products in these Arab countries was high. Studies with sound and reproducible methodology on the quality of medicines in developing countries are very limited Convenience sampling is widely used for this purpose, even though bias is clearly introduced because usually only accessible pharmacies or outlets are selected. Formal random sampling generally requires a larger sample, longer surveying time, and more resources.

Another study has conducted in community pharmacies in Riyadh a capital city of Saudi Arabia. A total of 83 samples from 72 pharmacies were collected and analysed. The samples were found to be authentic, but 9 were substandard because they failed to reach standard requirements, with 6 of the 9 averaging less than $90 \%$ of the labelled content. A problem existed with the quality of an essential drug in Riyadh's community pharmacies. Exposure to excessive temperature during distribution or storage has unfavourable on sequences on the quality of medicines, especially in hot weather. This could be one of the possible reasons behind the existence of substandard amoxicillin in Riyadh's CPs. However, inefficient quality control at the manufacturing stage cannot be excluded. The author recommend further studies to investigate the adherence of community pharmacies, and other facilities in the supply chain in Riyadh, to optimal conditions for keeping and selling medicines. He suggested larger-scale randomized surveys would be helpful to further delineate the scale of the quality-control problem in community pharmacies. A significant number of investigations and reports which observe the confiscation of counterfeit medicines by Saudi governments have been collected from Saudi newspapers and a massive amount of poor-quality medicines have been destroyed by the Ministry of Health and other cooperating institutes.

Moreover, In March 2014, the Ministry of Health in Saudi Arabia 
approved the decision to punish the owners of private pharmacies and drugstores - the total amount reached around 110 thousand riyals - due to violating the installations and pharmaceuticals system and its implementing regulations. They fined the owner of the pharmacy $\$ 60$ thousand riyals in addition to closing the pharmacy for a period of 60 days. These punishments were adopted after observing several irregularities, including the end of licensed pharmacies and the presence of counterfeit medicines adulterated and unregistered by the General Authority for Food and Drug Administration. The director of the inspection committee in the Food Drug Authority (FDA) mentioned that they adjusted adulterated drugs by less than $1 \%$ shortly after the withdrawal of more than 11 thousand samples from different regions of the Kingdom. Al dachas said that all of the other drugs did not prove any violation. The system has governed the Kingdom's serious medicines well since the entry of the drugs into the Saudi territory across all border crossing points, with inspectors being trained to control the entry of fake drugs and contraband. He pointed out that most countries in the world do not have special inspectors in the field of medicine outlets on the borders. On the other hand, the affairs of the Asia region and the General Directorate of Health Affairs and the Secretariat of the Asia region destroyed more than five thousand classes between counterfeit medicine Figure 4, as well as other slimming and fattening drugs carrying an unlicensed medical claim. The commission did frequent field trips to perfume shops and pharmacies, included in the provinces and centres of the Asia region, confiscating more than 5 thousand classes.

In March 2011 a team of Madinah secretariats confiscated more than 25 types of medicines and imitated sexual drugs. Some of them were global brands and the others were not licensed by the Ministry of Health, in addition to harmful herbs from perfumed shops. The team adjusted more than 300 tablets of Viagra and Cialis, 10 pills of golden honey, 61 grains of creams and ointments for the use of sex, in addition to illegal drugs for the treatment of diabetes and other diseases. In contrast, the security authority in Jazan region, the south region in Saudi Arabia, had managed, in coordination with the health affairs in Jazan, to thwart the smuggling of the biggest prohibited shipment of sexual medicines introduced to the Saudi border from Yemen. The experts estimate this case to be the largest shipment of drugs smuggled into Saudi Arabia (worth more than half a million Saudi riyal) [51-60].

\section{Analytical Identifications of Low Quality Medicines}

The identification of poor quality medicines has various types, four distinctive types of analysis can be used to distinguish between a genuine and substandard pharmaceutical substances, visual packaging, namely, authentication of the supplier, physical and chemical analysis the identification of medicines by authentication of sources could going through contact with health regulatory agencies, manufacturers and internet, while packaging inspection is more popular identification than authentication, the majority of packaging reporting spelling errors and basic label information's such as : medicines names, dosage form manufacturer, expiry dates and batch number. As for chemical analysis, thin layer chromatography(TLC), one of the most widely technique use in assess and identification of low quality of medicines, a study by bate et al. for anttuberculosis medicines in seventeen countries showed presence of substandard and counterfeited medicines with low or no active pharmaceutical ingredients. Another study has done by Ochekpe et al. in Nigeria for antimalarial drugs by use (TLC) showed presence of substandard medicines in $38 \%$ of the samples. another widely used technique which is high performance liquid chromatography (HPLC), a study by khan et al. in Cambodia using (HPLC) for identification different brands of antifungal medicines showed presence of substandard continents with less percentage, while another study has done by taylor et al. for antimalarial and antibiotics medicines in Nigeria and Thailand emerged of around of $40 \%$ of drugs are substandard with low or high (API). Moreover, ultra violet technique used by ali et al. for antimalarial drugs identification in Nigeria, this study showed about $50 \%$ of medicines are substandard. While another study has done by use both (UV) and (HPLC) for assess antimalarial and antibiotics medicines in Cameroon and Niger, the results showed presence of $43 \%$ of medicines are substandard. Additionally, Liquid chromatography mass spectrometry (LC-MS) is another technique which has used in seven different countries to identify anti tuberculosis medicines, the result showed about $10 \%$ of medicines are substandard, with low API. Another study by use HPLC-MS has done in India by Seear et al. for assess and identify ciprofloxacin as an antibiotic, the results showed $43 \%$ of medicines substandard with low and high API.

Near infra-red spectroscopy one of the most widely technique that uses the near infra-red region of the electromagnetic spectrum (from about $800 \mathrm{~nm}-2500 \mathrm{~nm}$ ) historically, the discovery of the NIR spectra in 1800 is credited to Herschel who separated the electromagnetic spectrum Although a number of NIR experiments were carried out in the early 1920s, it was not before the mid to late1960s that NIR spectroscopy was practically used. It was Karl Norris from the U.S. Department of Agriculture who recognized the potential of this analytical technique The American Society of Testing and Materials (ASTM) defines the NIR region of the electromagnetic spectrum as the wavelength range of 780-2526 nm corresponding to the wave number range $12820-3959 \mathrm{~cm}^{-1}$. The most prominent absorption bands occurring in the NIR region are related to overtones and combinations of fundamental vibrations of $-\mathrm{CH},-\mathrm{NH},-\mathrm{OH}$ (and $-\mathrm{SH}$ ) functional groups carried out with different application such as pharmaceutical and medical diagnosis. One of advantage of NIR that can typically penetrate much farther into a sample than mid infra radiation. So it can be very useful in probing bulk material with little or no sample preparation. A chemometric application are often employed to extract the desired chemical information so it is essential for near-infrared analytical methods. NIR has been used in the literature for the detection of low quality medicines in some international markets. An analytical comparative study by Said, using (NIR) for paracetamol in Malaysia and UK, the study represented variable quality of paracetamol in different brands furthermore a study in several African countries has done by bate et al. for antimicrobial and antibiotics medicines using near infra- 
red spectroscopy showed $51 \%$ of samples were substandard with low API. It can be concluded that NIR is a powerful analytical tool for identification and quantification of medicines, and provides both chemical and physical information for better assessment of samples. However, it is mostly used as a screening tool, as it cannot identify unknown samples, other complementary techniques are needed for identification such as HPLC, Nuclear Magnetic Resonance (NMR) or Liquid Chromatography-Mass Spectrometry

Nuclear Magnetic Resonance (NMR) spectroscopy is an analytical chemistry technique used in quality control and research for determining the content and purity of a sample as well as its molecular structure. NMR used by chemists and biochemists to investigate the properties of organic molecules, NMR spectroscopy was discovered in 1945 by Bloch at Stanford and Purcell at Harvard University. Initially, NMR belonged to the science of physics but after the discovery of the chemical shift (i.e. nuclei in different chemical surroundings have different resonance frequencies) the technique quickly became very important as an analytical tool in chemistry. NMR has also become an important tool for the qualitative and quantitative analysis of complex mixtures such as herbal medicines. Although it is applicable to any kind of sample that contains nuclei possessing spin, that when the spin quantum number of these nuclei's is bigger than zero. Moreover, NMR spectra is highly unique, well-resolved, analytically tractable and often highly predictable for small molecules. Most frequently, the Suitable samples range from small compounds analyzed with 1-dimensional proton or carbon${ }^{13} \mathrm{NMR}$ spectroscopy to large proteins or nucleic acids using 2 or 3-dimensional techniques. The proton and carbon spectra can be analysed in terms of number of signals(environment), in tensities of the signals(peak area), position of signals(chemical shifts), and splitting of signals to several peaks(coupling). ${ }^{1} \mathrm{H}$ spectra are the most commonly used spin $1 / 2$ nucleus in NMR investigation. Hydrogen is highly abundant, especially in biological systems. It is the nucleus most sensitive to NMR signal. Proton NMR produces narrow chemical shift with sharp signals. Fast acquisition of quantitative results (peak integrals in stoichiometric ratio) is possible due to short relaxation time. The ${ }^{1} \mathrm{H}$ signal has been the sole diagnostic nucleus used for clinical magnetic resonance imaging. NMR has been used in the literature for the detection of low quality medicines. An analytical study by Ulrike Holzgrabe, institute of pharmacy and food chemistry in Germany in 2010, which confirmed that the NMR spectroscopy being a primary ratio method of measurement, that because it is highly suitable to identify and quantify a medicines and its related substances as well as to investigate a medicines of sub-standard quality.

Also , in 2007 the results obtained in study done by Saleh Torefi for analysis of eight formulations of tadalafil by complementary analytical methods (Raman spectroscopy, ${ }^{1} \mathrm{H}$ NMR, and LCMS) showed that the NMR is a powerful tool for screening of pharmaceutical formulations and checking the quality of drugs, its allow detecting of active pharmaceutical ingredients and excipients. Moreover, an analytical study by Stéphane Balayssac et al. for the analysis of herbal drugs and dietary supplements, confirmed that $2 \mathrm{DOSY}^{1} \mathrm{H}$ NMR spectroscopy is a powerful method for providing a multivariate fingerprint of a complex mixture especially in situations where the identity of the components is not known beforehand. Furthermore, in 2014 a study by Véronique Gilarda et al. for detection, identification and quantification by ${ }^{1} \mathrm{H}$ NMR of adulterants in 150 herbal dietary supplements marketed for improving sexual performance in this study the researcher demon-started that ${ }^{1} \mathrm{H}$ NMR spectroscopy can be used as a first line method for quality control of such dietary supplements . Indeed, it allows the detection and quantification of all adulterants and clearly brings out structural differences between analogues. Finally, NMR is an ideal technique for quality assessment of API and excipients, even for both identification and quantification of single medicines and complex herbal mixture. Other complementary techniques are needed for identification such as HPLC, near infra-red (NIR) or Liquid Chromatography-Mass Spectrometry [61-70].

\section{Sampling Strategy}

Sampling technique is a project which involves the selection of a number of study units from a defined study population. When drawing a sample, a researcher first needs to decide which population intends to study. This depends on the research objectives and questions. Sampling strategies need to be defined as you can rarely cover every person in the selected population, so there is simply not enough; time, energy, money, labour/man power, equipment, access to suitable sites to measure every single item or site within the parent population or whole sampling frame. There are many types of sampling techniques, the probability sampling is one of sampling technique in which each sample has the same probability of being chosen, e.g. simple random sampling, cluster sampling, and stratified sampling.

Simple random sampling is a type of probability sampling technique, with the simple random sample, there is an equal chance (probability) of selecting each unit from the population being studied when creating sample. The most advantage of random sampling which can be used with large population's samples without bias, nevertheless, the results can lead to poor representation of the overall parent population or area if large areas are not hit by the random numbers generated. Nonprobability sampling techniques is that samples are selected based on the subjective judgement of the researcher, rather than random selection, which is the cornerstone of probability sampling techniques. Whilst some researchers may view nonprobability sampling techniques as inferior to probability sampling techniques e.g. quota sampling, convenience sampling, purposive sampling. A convenience sample is simply one where the units that are selected for inclusion in the sample are the easiest to access Convenience sampling is very easy to carry out with few rules governing how the sample should be collected.

The relative cost and time required to carry out a convenience sample are small in comparison to probability sampling techniques. Nevertheless the convenience sample often suffers from biases. In contrast, different sample sizes were used in the 
literature, usually depending on the scope and resources available typically, countries with established scientific evidence of low quality of medicine problem require a larger sample size from different locations. Moreover, studies with the aim of quantifying the prevalence rate of low quality of medicines would require an increased number of samples with an appropriate sampling method. Nevertheless, studies reporting randomized sampling are scarce while the vast majority of published articles employ convenient sampling.

For the purpose of this study, at least 3 different brands of medicines will be collect from community pharmacies from four regions of each cities and central public hospital, Further; all different trade names available for the selected medicine will be collected using the same approach. Samples from Saudi and UK brand name manufacturer could also be included in the study for comparison.

The type of medicines will be collect depend on stability of medicines, narrow therapeutic index medicines, highly cost medicines and cases of substandard and counterfeited with these kinds of drugs. The following table represent the most medicines with all of these certain criteria (Table 1).

\section{Hypothesis and Research Questions}

\section{Primary question}

To what extent the proliferation of low-quality medicines in Saudi pharmaceutical market?

\section{Second questions}

- How can be confirm the poor quality of confiscated medicines samples and how can establish the protocol for analysis of medicines?

- How can assess the prevalence of substandard medicine in the Saudi market, and how can explore a possible link between quality of medicine and geographical proximity of pharmacies a possible source of counterfeit medicine?

- What are the perceptions of private health care providers about the quality of medicines in Saudi Arabia

\section{Aim and Objective}

\section{Aim}

This research project aims to investigate and assess the quality of selected essential medicines in different cities in Saudi Arabia. In addition, this project will compare the findings in order to draw

Table 1 most common essential medicines.

\begin{tabular}{|c|c|c|c|c|c|c|c|c|c|}
\hline Drugs & Warfarin & L thyroxin & Sildenafil & Paracetamol & Clopidogrel & Digoxin & Chloroquine & Atorvastatin & $\begin{array}{l}\text { Amoxicillin } \\
+ \\
\text { Clavulanic } \\
\text { Acid }\end{array}$ \\
\hline $\begin{array}{l}\text { Physical } \\
\text { Cindition }\end{array}$ & $\begin{array}{c}\text { Store at room } \\
\text { temp } 25^{\circ} \mathrm{C}\end{array}$ & $\begin{array}{l}\text { Store at room } \\
\text { temp } 25^{\circ} \mathrm{C}\end{array}$ & $\begin{array}{c}\text { Stable } \\
\text { at room } \\
\text { temperature } \\
25^{\circ} \mathrm{C}\end{array}$ & $\begin{array}{c}\text { Stable } \\
\text { at room } \\
\text { temperature } \\
25^{\circ} \mathrm{C}\end{array}$ & $\begin{array}{c}\text { Stable } \\
\text { at room } \\
\text { temperature } \\
25^{\circ} \mathrm{C}\end{array}$ & $\begin{array}{l}\text { Store in a dry } \\
\text { place and } \\
\text { protect from } \\
\text { light, Store } \\
\text { at controlled } \\
\text { room } \\
\text { temperature } \\
15 \text { to } 30^{\circ} \mathrm{C}\end{array}$ & $\begin{array}{c}\text { Store at } \\
\text { controlled } \\
\text { room } \\
\text { temperature } \\
15 \text { to } 30^{\circ} \mathrm{C} \text {, } \\
\text { Store away } \\
\text { from heat, } \\
\text { moisture, } \\
\text { and light }\end{array}$ & $\begin{array}{c}\text { Store at } \\
\text { controlled room } \\
\text { temperature } 15 \\
\text { to } 30^{\circ} \mathrm{C} .\end{array}$ & $\begin{array}{l}\text { Stable at } \\
\text { room } \\
\text { temp } 25^{\circ} \mathrm{C} \\
\text { effect by } \\
\text { humidity }\end{array}$ \\
\hline $\begin{array}{c}\text { Therapeutic } \\
\text { index }\end{array}$ & $\begin{array}{l}\text { Narrow } \\
\text { therapeutic } \\
\text { index }\end{array}$ & $\begin{array}{l}\text { Narrow } \\
\text { therapeutic } \\
\text { index }\end{array}$ & $\begin{array}{l}\text { Broad } \\
\text { therapeutic } \\
\text { index }\end{array}$ & $\begin{array}{l}\text { Broad } \\
\text { therapeutic } \\
\text { index }\end{array}$ & $\begin{array}{l}\text { Broad } \\
\text { therapeutic } \\
\text { index }\end{array}$ & $\begin{array}{c}\text { Narrow } \\
\text { therapeutic } \\
\text { index }\end{array}$ & $\begin{array}{c}\text { Narrow } \\
\text { therapeutic } \\
\text { index }\end{array}$ & $\begin{array}{l}\text { Broad } \\
\text { therapeutic } \\
\text { index }\end{array}$ & $\begin{array}{l}\text { Broad } \\
\text { therapeutic } \\
\text { index }\end{array}$ \\
\hline Use & Anticoagulant & $\begin{array}{c}\text { Treatment of } \\
\text { hypothyroidism }\end{array}$ & $\begin{array}{c}\text { Erectile } \\
\text { disfunction. }\end{array}$ & $\begin{array}{l}\text { Antipyretic/ } \\
\text { Analgesic }\end{array}$ & $\begin{array}{c}\text { Anticoagulant } \\
\text { agents }\end{array}$ & $\begin{array}{l}\text { Treatment of } \\
\text { heart failure }\end{array}$ & $\begin{array}{l}\text { Drug of } \\
\text { choice for } \\
\text { treatment } \\
\text { malaria } \\
\text { infections }\end{array}$ & $\begin{array}{l}\text { Drug of choice } \\
\text { for hyper } \\
\text { cholesterol } \\
\text { treatment }\end{array}$ & $\begin{array}{l}\text { Drug of } \\
\text { choice for } \\
\text { several } \\
\text { infections }\end{array}$ \\
\hline $\begin{array}{l}\text { Issues for } \\
\text { quality }\end{array}$ & Not specified & Not specified & $\begin{array}{l}\text { Much } \\
\text { cases of } \\
\text { counterfeit } \\
\text { observed }\end{array}$ & $\begin{array}{c}\text { Two of } \\
\text { ninesamples } \\
\text { failed to } \\
\text { meet USP } \\
\text { dissolution } \\
\text { test in } \\
\text { Tanzania }\end{array}$ & $\begin{array}{l}\text { Two of } 18 \\
\text { generics } \\
\text { failed the } \\
\text { dissolution } \\
\text { test } \\
\text { according } \\
\text { to USP and } \\
\text { Sanofi- } \\
\text { Aventis } \\
\text { specifications }\end{array}$ & Not specified & $\begin{array}{c}\text { Frequent } \\
\text { cases of } \\
\text { poor quality } \\
\text { observed in } \\
\text { Africa }\end{array}$ & $\begin{array}{l}\text { Counterfeit } \\
\text { case in } 2006 \\
\text { detected by } \\
\text { medicines } \\
\text { health } \\
\text { regulatory } \\
\text { authority } \\
\text { (MHRA) in UK }\end{array}$ & $\begin{array}{l}\text { Low } \\
\text { quality } \\
\text { cases have } \\
\text { been } \\
\text { observed }\end{array}$ \\
\hline Price & $3 \$ /$ package & $10 \$ /$ package & $80 \$ /$ package & 3\$/package. & $80 \$ /$ package & 45\$/package & 10\$/package & 52\$/package & $\begin{array}{c}27 \$ / \\
\text { package }\end{array}$ \\
\hline
\end{tabular}


further conclusions on how to explore the substandard medicines in Saudi pharmaceutical markets.

\section{Objectives}

The specific objective of this study: To certify and confirm the poor quality of confiscated samples and establish the plans for analysis of medicines samples. To explore a possible link between quality of medicines and geographical proximity of community pharmacies to a possibly source of counterfeit medicine. Link between high influx of visitors to major events and quality of medicine available in the local market. To explore health care providers perceptions of quality of medicines, and its relationship of observed quality of selected medicines.

\section{Study of Substandard Medicines in Developing Countries}

\section{Introductions}

Amoxicillin is safe, very popular antibiotics, its broad spectrum, beta lactam antibiotic, active against limited range of $G-v e$ organism, and wide range of $\mathrm{G}+\mathrm{ve}$ organism. It is a drug of choice for treatment various types of infections because it is better absorbed, low cost least toxicity, following oral administration, compared to other beta lactam antibiotics. Amoxicillin is the first became available in 1972. It is favourable for children as a first option. Among antibiotics, amoxicillin is widely used in developing countries, and it is included in the list of essential medicines issued by the World Health Organization (WHO). It is also considered a principle medicine in primary health care in Saudi Arabia. It is also among the most widely counterfeited medicines in developing countries. Substandard amoxicillin has already been identified in Saudi Arabia in one study. Antibiotic resistance is a global issue, threatens at all levels of health care and globally, challenges public health interventions. And The US Centre's for Disease Control and Prevention (CDC) considers antibiotic resistance one of their top concerns. Infections with drug-resistant bacteria may lead to longer and more costly hospital care, and may increase the risk of dying from the infection. For example, people with MRSA (methicillin-resistant Staphylococcus aureus) are estimated to be $64 \%$ more likely to die than people with a non-resistant form of the infection. With the high market of antibiotics, the substandard products will also play part to the resistance incidence. A substandard antibiotic may cause therapeutic failure due to the lower dosage or absence of the active compounds that finally induce antimicrobial resistance, increase morbidity, mortality and significant economic burden on developing countries. In addition, substandard narrow-spectrum antibiotics may make prescriber think that the antibiotics are not effective, thus unnecessarily prescribe a newer broad-spectrum antibiotics as their first-line treatment for many infections. Moreover, Antibiotic prescriptions and cases of resistant bacteria in England have continued to increase despite warnings and campaigns, the Public Health in England found a six percent increase in prescriptions between 2010 and 2013 and warned that up to half may be "inappropriate". It found a link between areas of high prescribing and resistant bacteria. About 5,000 people a year die in Britain from infections that are resistant to antibiotics, and drug resistance is growing steadily, eroding the effectiveness of doctors' most powerful antibiotics. Furthermore, the presence of substandard, or counterfeit, antibiotics is caused by the high prevalence of low income citizens in the developing countries that make the market exist. People with low-income and without any health insurance scheme will purchase medicine, including antibiotics, as cheap as possible. This is accompanied with insufficient regulations and manufacturing control from the authorities. This has been attributed to the misuse of antibiotics by physicians, unskilled practitioners, and the public. In developing countries, substandard medicines are only one aspect of poor quality antibiotics, with other issues including a lack of adherence and monitoring, degraded antibiotics often due to inadequate storage in both pharmacies and in the supply chain, expired antibiotics distributed from developed countries, and bioequivalent antibiotics. Between 1981 and 1995, resistance to ampicillin, tetracycline, sulphonamides, chloramphenicol, flour quinolones, isoniazid, streptomycin, and rifampicin was shown to be increasingly prevalent across the following developing and tropical countries: Bangladesh, Brazil, Rwanda, Thailand, India, Kenya, and Morocco. In addition, the West African country of Sierra Leone ranks as one of the least developed and poorest countries in the world, with three-fourths of the 6 million populations living below the poverty line. In June, 2009, a member of the Pharmacy Board of Sierra Leone reported that more than $\$ 150$ million worth of substandard drugs is brought into Sierra Leone alone every year. A set of substandard amoxicillin has analysed in this study using nuclear magnetic resonance technique. NMR spectroscopy is highly suitable for quality assessment of an API or excipients, because it can be used for many purpose including both identification and quantification. The aim of this study is to investigate the presence of substandard medicines in community pharmacies in Sierra Leone. Also to explore the need to monitor and assess the quality of medicines in retail and wholesale pharmaceutical markets in developing countries $[71,72]$.

\section{Material and method}

A set of different brands of amoxicillin capsules have been analysed in this study with a total of six samples as Figure 1.The samples of this study were collected last year, Ms Fry has visited Free town a capital city of Sierra Leone and she was observed miserable condition for some medicine markets, so she interest to purchase a set of amoxicillin samples, she use a convenient sampling an approach at undisclosed location in sierra Leone. The samples shipped and analysed in Hertfordshire university laboratories. The $100 \mathrm{mg}$ of sample was dissolved in $\mathrm{D}_{2} \mathrm{O}$ and $100 \mathrm{mg}$ of sample was dissolved in $\mathrm{CD}_{3} \mathrm{OD}$. The dissolved samples were vortexes for 30 seconds, followed by centrifugation. The supernatants were filtered when transferred into NMR tubes the ${ }^{1} D^{1} \mathrm{H}$ and ${ }^{1} \mathrm{H}^{2} \mathrm{D}$ COSY NMR spectra were performed on a DELTA NMR 600 spectrometer operating at $600.17 \mathrm{MHz}$ equipped with a $5-\mathrm{mm}$ Proton probe at $298 \mathrm{~K}$ on $600 \mu \mathrm{l}$ samples. Typical acquisition parameters for the ${ }^{1} \mathrm{H}$ NMR Experiments were as follows: acquisition time $2.909 \mathrm{~s}$, spectral width $10000 \mathrm{~Hz}$, pulse 
width $6.125 \mu$ s, relaxation delay 4 sand numbers of scans 32 (Table 2).

\section{Result and discussion}

Initially, the weighting of the content of the capsules has provided clear indication that some of the amoxicillin samples are substandard. The total weight for amoxicillin capsule sample 3 , show with $230 \mathrm{mg}$ less than declared active pharmaceutical ingredients(API), which that confirmed low quality of Jawa Indian pharmaceutical, also the total weight of amoxicillin sample 4 show the amount less than approved active pharmaceutical ingredients, with $530 \mathrm{~g}$ capsule total weight. Furthermore sample 5 indicate the close weight of total capsule weight to (API).The list of the amoxicillin samples with declared antibiotic doses and actual weight of the capsule content $\mathrm{s}$ for each sample, shown in Table 3 below.

In NMR spectra, the amoxicillin structure diagnose by the position of the peak and number of chemical shift. The position peak of the $\mathrm{CH}^{\sim}$ methyl group 1 and 2 In $\mathrm{H}^{\sim N M R}$ spectra, represent in 1.36 and $1.37 \mathrm{ppm}$, while the $\mathrm{H}^{\sim N M R}$ aromatic group represent in 6.92 and $7.31 \mathrm{ppm}$, the position peak $4.71 \mathrm{ppm}$ represent $\mathrm{H}_{2} \mathrm{O}$ solvent.

Furthermore deaerated methanol $\mathrm{CD}_{3} \mathrm{OD}$ peak show in $3.31 \mathrm{ppm}$. in the following figures the chemical structure of amoxicillin with chemical group numbering, and spectra of amoxicillin sample. In this experiment, the amoxicillin samples dissolved in $\mathrm{D}_{2} \mathrm{O}$, show variation in chemical shifts, the Amoxicillin sample 4 chemical shifts seems to be close to chemical shift to literature reference data, despite sample 6 chemical shift data in $\mathrm{CD}_{3} \mathrm{OD}$ show near to literature reference data. The following tables interpret the $H^{\sim N M R}$ chemical shift data of amoxicillin in $\mathrm{D}_{2} \mathrm{O}$ and $C D_{3} \mathrm{OD}$. On other hand the overlay the spectra of amoxicillin of various brand names Figure 6, illustrate and confirm the presence of active pharmaceutical ingredients (API) in all samples (Figure 7), furthermore the main inactive pharmaceutical ingredients use in amoxicillin samples are magnesium stearate and silica colloidal anhydrous, which Mg Stearate can use as lubricants to improve the flow of powder and preventing ingredients from sticking to manufacturing equipment during the compression of chemical powders, (Mg Stearate) represent variation In molecular ratio between the amoxicillin samples, it show the highest level in sample 2 and lowest in sample 4, also additional peaks around
1.15 ppm were observed in samples 2, 4 and 5 which could be attributed to possible excipients. What are common excipients in Amoxicillin capsules. The area under the NMR signal is directly proportional to the number of protons giving rise to the signal. The following Table 4 show area under the curve for ${ }^{1} \mathrm{H}$ NMR spectra of Amoxicillin. In amoxicillin sample 2 the molar ratio between $\mathrm{API}$ and $\mathrm{Mg}$ st is close to four, while the molar ratio in sample one equal to zero between the API and unknown excipient which give evidence of low quality of this sample. In general the nuclear magnetic resonance (NMR) spectra of Sierra Leon amoxicillin samples showed the variations in pharmacological relevant quantities of pharmaceutical active ingredients as well as excipients, despite that amoxicillin sample no two seemed to be the most closer to the standard as compared to other samples. However, it is still below the required limit. The consumption of these samples would have been ineffective for medical treatment and could potentially contribute to developing new strains of bacterial resistance to antibiotics.

The API in Pakistani samples was identified in all samples within the pharmacological relevant quantities. Moreover the weight of amoxicillin powder identified the high quality of these samples. This gives an indication of the effectiveness of the Pakistani amoxicillin samples and its validity for medical consumption without potentially any adverse effects. Moreover, there are a few literature studies focus on identification and analysis of amoxicillin by NMR, nevertheless a study by Ivan Hameed in synthesis and characterization of amoxicillin derivatives give useful and referenced H NMR data, and perfect interpretation of amoxicillin NMR spectra. Furthermore, NMR spectroscopy is highly suitable for quality assessment of an API or excipient's, because it is powerful tool for screening of pharmaceutical formulations and checking the quality of drugs, its allow detecting of active pharmaceutical ingredients and excipients, in addition it can evaluate the level of impurities and the residual solvents (Table 5) Finally, this study carried out with one type of antibiotics and few samples selected in Sierra Leone and Pakistan medicines markets, but it does not reflect the reality of the medicines market in those countries. Additional studies covering different classes of medicines and large samples of medicines might be needed to give accurate findings about the quality of medicines especially in Sierra Leone pharmaceutical markets (Figure 7).

Table 2 Formulation of amoxicillin analysed.

\begin{tabular}{|c|c|c|c|c|c|}
\hline Formulation & Batch & Expiry date & Dosage form & Manufacture & Country of \\
\hline Name & Number & & & Name & Manufacture \\
\hline Floximox & $5160307 \mathrm{~F}$ & May-15 & 250 (capsule) & Evans & Nigeria \\
\hline Amoxil & AR 3061 & Feb-16 & 500 (capsule) & beecham & united kingdom \\
\hline Jawamox & ME1133 & Dec-14 & 250 (capsule) & Jawa & India \\
\hline Amoxigram & 1534370 & Jun-15 & 500 (capsule) & Hovid & India \\
\hline Vitamox & unknown & Apr-15 & 500 (capsule) & vital & India \\
\hline Vitamox & Unknown & Apr-15 & 250 (capsule) & Vital & India \\
\hline Amoxil & Cafan 15 & Jun-15 & 250(capsule) & GSK & Pakistan \\
\hline Wymox & 16H1991 & Aug-15 & 500(capsule) & Macter & Pakistan \\
\hline jaxcil & B6 & Aug-16 & 250(capsule) & irza pharma & Pakistan \\
\hline
\end{tabular}


Table 3 Variation of amoxicillin tablets weight.

\begin{tabular}{|c|c|c|}
\hline Sample & Declared Amx content(mg) & \multicolumn{2}{c|}{ Total weight of cap content(mg) } \\
\hline Amoxicillin 1 & 250 & 570.7 \\
\hline Amoxicillin 2 & 500 & 230.2 \\
\hline Amoxicillin 3 & 250 & 490 \\
\hline Amoxicillin 4 & 500 & 530.5 \\
\hline Amoxicillin 5 & 500 & 210.5 \\
\hline Amoxicillin 6 & 250 & 290 \\
\hline Amoxicillin 7 & 250 & 570 \\
\hline Amoxicillin 8 & 500 & 292 \\
\hline
\end{tabular}

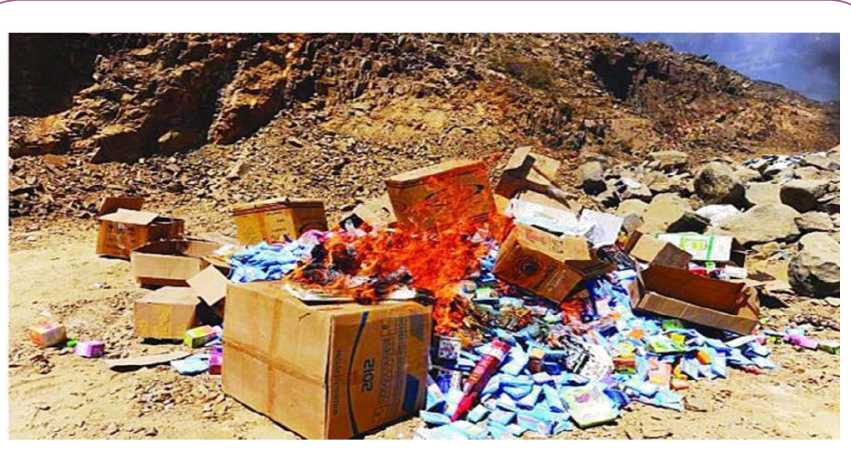

Figure 6 Counterfeiting medicine destroyed in Asir.

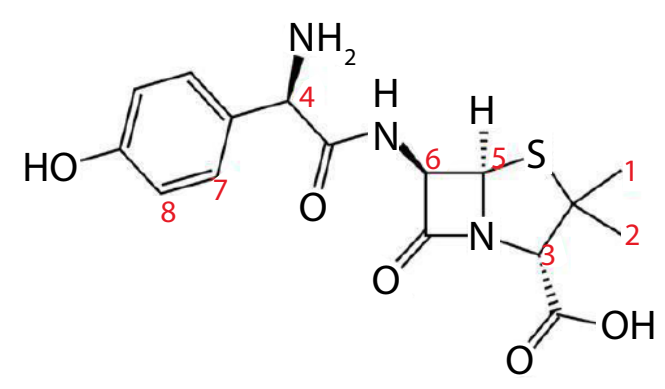

Figure 7 Amoxicillin sample.

\section{Study of Substandard Sildenafil and Tadalafil}

\section{Introductions}

Sildenafil citrate (Viagra, Pfizer), vardenafil hydrochloride (Levitra, Bayer) and tadalafil (Cialis, Elli Lilly) (Figure 1) are marketed as approved drugs for the treatment of erectile dysfunction (ED) in males. The drugs used are potent inhibitors of phosphodiesterase type-5(PDE-5), which is responsible for degradation of guano sine monophosphate (cGMP). They also find use for pulmonary hypertension, Raynaud's phenomenon, altitude sickness and Duchene /Becker muscular dystrophy .ED occurs commonly (i.e. up to $60-70 \%$ ) in patients with hypertension and ischemic heart disease. Viagra and Cialis are one of the most counterfeited classes of medicines. In United Kingdom, in 2012 huge amount of counterfeit Viagra and Cialis Smuggled into the UK. Contained undeclared active Ingredients with possible serious health risks to the consumer. Moreover, In March 2007, the Health Ministry in Malaysia seized 1.4 million capsules of counterfeit erectile dysfunction medicines worth MYR\$14 million (US\$4 million) from a container in Penang. In March 2011, more than a dozen pharmacists were indicted in Korea for the first time for distributing Counterfeit Viagra pills that were manufactured in China. The Saudi food drug authority in Saudi Arabia has responsibilities for inspect and confiscate substandard and illegal medicines from community pharmacies or from any supply chain process. In this study, a set of substandard Viagra, Cialis and Snafi pills which has been collected from SFDA, after confiscated from different community pharmacies in different cities in Saudi Arabia, to ensure the variation between the original and substandard one.

\section{Method and materials}

The researcher has collected a set of substandard erectile defunction medicines Viagra, Cialis and Snafi, from Saudi food drug authority in July 2014, the substandard medicines has confiscated by SFDA through inspection rounds on the community pharmacies of different city in Saudi Arabia, the medicines has brought to Hertfordshire university laboratory to analysis and assessment. The $100 \mathrm{mg}$ of sample was dissolved in $\mathrm{CD}_{3} \mathrm{OD}$. The dissolved samples were vortexes for 30 seconds, followed by centrifugation. The supernatants were filtered when transferred into NMR tubes the ${ }^{1} \mathrm{D}{ }^{1} \mathrm{H}$ and ${ }^{1} \mathrm{H} 2 \mathrm{D}$ COSY NMR spectra were performed on a DELTA NMR 600 spectrometer operating at 600.17 MHz equipped with a 5-mm Proton cryoprobe at $298 \mathrm{~K}$ on $600 \mu \mathrm{l}$ samples. Typical acquisition parameters for the ${ }^{1} \mathrm{H}$ NMR Experiments were as follows: acquisition time $2.909 \mathrm{~s}$, spectral width $10000 \mathrm{~Hz}$, pulse width $6.125 \mu$ s, relaxation delay 4 sand number of scans 32 .

\section{Results and discussion}

In a first step, the genuine and substandard formulations of Viagra, Cialis and Snafi were checked by analysing separately one tablet of each batch. The three genuine ${ }^{1} \mathrm{H}$ NMR spectra were identical, thus providing a 'spectral signature' representative of the brand formulations. In genuine Viagra the only constituent of the tablet core that was detected is the active pharmaceutical ingredients sildenafil as magnesium stearate, which is soluble in deuterated methanol, despite other pharmaceutical ingredients are those of the coating, i.e. lactose, hypromellose and triacetine were not observed which not soluble in methanol. Sodium lauryl 
Table $4 \mathrm{H}$ NMR data of amoxicillin in $\mathrm{D}_{2} \mathrm{O}$.

\begin{tabular}{|c|c|c|c|c|c|c|c|}
\hline Assignment & Amoxicillin & Amoxicllin 1 & Amoxicllin 2 & Amoxicllin 3 & Amoxicllin 4 & Amoxicllin 5 & Amoxicllin6 \\
\hline A-CH3 & $1.36(\mathrm{~s})$ & $1.297(\mathrm{~s})$ & $1.294(\mathrm{~s})$ & $1.294(\mathrm{~s})$ & $1.295(\mathrm{~s})$ & $1.298(\mathrm{~s})$ & $1.293(\mathrm{~s})$ \\
\hline B-CH3 & $1.37(\mathrm{~s})$ & $1.310(\mathrm{~s})$ & $1.310(\mathrm{~s})$ & $1.309(\mathrm{~s})$ & $1.311(\mathrm{~s})$ & $1.310(\mathrm{~s})$ & $1.310(\mathrm{~s})$ \\
\hline H-3 & $4.09(\mathrm{~s})$ & $4.031(\mathrm{~s})$ & $4.032(\mathrm{~s})$ & $4.0306(\mathrm{~s})$ & $4.034(\mathrm{~s})$ & $4.031(\mathrm{~s})$ & $4.034(\mathrm{~s})$ \\
\hline $\mathbf{H}-10$ & $4.85(\mathrm{~s})$ & $4.654(\mathrm{~s})$ & $4.652(\mathrm{~s})$ & $4.666(\mathrm{~s})$ & $4.695(\mathrm{~s})$ & $4.650(\mathrm{~s})$ & $4.652(\mathrm{~s})$ \\
\hline H-5 & $5.07(\mathrm{~m})$ & $5.017(\mathrm{~m})$ & $5.033(\mathrm{~m})$ & $5.032(\mathrm{~m})$ & $5.034(\mathrm{~m})$ & $5.012(\mathrm{~m})$ & $5.034(\mathrm{~m})$ \\
\hline H-6 & $5.44(\mathrm{~m})$ & $5.383(\mathrm{~m})$ & $5.384(\mathrm{~m})$ & $5.383(\mathrm{~m})$ & $5.385(\mathrm{~m})$ & $5.383(\mathrm{~m})$ & $5.383(\mathrm{~m})$ \\
\hline Ha & $6.92(\mathrm{~d})$ & $6.866(\mathrm{~d})$ & $6.868(\mathrm{~m})$ & $6.866(\mathrm{~m})$ & $6.869(\mathrm{~d})$ & $6.865(\mathrm{~d})$ & $6.867(\mathrm{~d})$ \\
\hline Hb & $7.31(\mathrm{~d})$ & $7.257(\mathrm{~d})$ & $7.259(\mathrm{~m})$ & $7.255(\mathrm{~m})$ & $7.260(\mathrm{~d})$ & $7.256(\mathrm{~d})$ & $7.259(\mathrm{~d})$ \\
\hline NH & $8.68(\mathrm{~d})$ & Not observed & Not observed & Not observed & Not observed & Not observed & Not observed \\
\hline OH & $9.05(\mathrm{~d})$ & Not observed & Not observed & Not observed & Not observed & Not observed & Not observed \\
\hline
\end{tabular}

Table 5 H NMR data of amoxicillin in $\mathrm{CD}_{3} \mathrm{OD}$.

\begin{tabular}{|c|c|c|c|c|c|c|c|}
\hline Assignment & Amoxicillin & Amoxicllin 1 & Amoxicllin 2 & Amoxicllin 3 & Amoxicllin 4 & Amoxicllin 5 & Amoxicllin 6 \\
\hline A-CH3 & $1.38(\mathrm{~s})$ & )1.466(s) & 1.467 (s & 1.468(s) & $1.468(\mathrm{~s})$ & $1.468(\mathrm{~s})$ & $1.465(\mathrm{~s})$ \\
\hline $\mathrm{B}-\mathrm{CH} 3$ & $1.49(s)$ & $1.505(\mathrm{~s})$ & $1.504(\mathrm{~s})$ & $1.505(\mathrm{~s})$ & $1.504(\mathrm{~s})$ & $1.506(\mathrm{~s})$ & $1.501(\mathrm{~s})$ \\
\hline H-3 & $3.98(s)$ & $4.088(s)$ & $4.090(\mathrm{~s})$ & $4.089(\mathrm{~s})$ & $4.090(\mathrm{~s})$ & $4.090(s)$ & 4.094(s) \\
\hline H-10 & $4.87(s)$ & $4.847(s)$ & $4.846(\mathrm{~s})$ & $4.842(s)$ & $4.837(s)$ & $4.846(\mathrm{~s})$ & $4.846(\mathrm{~s})$ \\
\hline H-5 & $5.32(d)$ & $5.394(\mathrm{~m})$ & $5.395(\mathrm{~m})$ & $5.395(\mathrm{~m})$ & $5.394(\mathrm{~m})$ & $5.396(\mathrm{~m})$ & $5.395(\mathrm{~m})$ \\
\hline H-6 & $5.50(\mathrm{~m})$ & $5.505(\mathrm{~m})$ & $5.505(\mathrm{~m})$ & $5.505(\mathrm{~m})$ & $5.508(\mathrm{~m})$ & $5.504(\mathrm{~m})$ & $5.507(\mathrm{~m})$ \\
\hline $\mathrm{Ha}$ & $6.77(d)$ & $6.824(d)$ & $6.826(d)$ & $6.823(d)$ & $6.827(d)$ & $6.824(d)$ & $6.829(d)$ \\
\hline $\mathbf{H b}$ & 7.30(d) & $7.263(d)$ & $7.264(d)$ & $7.261(d)$ & $7.264(d)$ & $7.262(d)$ & $7.267(d)$ \\
\hline \multirow[t]{2}{*}{ NH } & $8.68(d)$ & & & & & & \\
\hline & & Not observed & Not observed & Not observed & Not observed & Not observed & Not observed \\
\hline $\mathrm{OH}$ & $9.05(d)$ & Not observed & Not observed & Not observed & Not observed & Not observed & Not observed \\
\hline
\end{tabular}

sulphate and magnesium sulphate were detected in genuine Cialis and Snafi tablets, while other core constituents not observed such as lactose, hypromellose and triacetine. The peak at $3.31 \mathrm{ppm}$ corresponds to the signal of solvent $\mathrm{CD}_{3} \mathrm{OD}$. All the peaks of sildenafil and tadalafil are lined up, chemical structure, reference spectra chart and the chemical shifts of these active compounds are reported as following:

In this experimental the $\mathrm{H}$ NMR chemical shift of Sildenafil represent in methyl group at ppm $0.95(t, j=8.0 \mathrm{~Hz}), 1.42$ $(t, j=8.0 \mathrm{~Hz})$, singlet and quadruplet proton at $4.20(\mathrm{~s})$ and $4.29(\mathrm{~d}, \mathrm{j}=8.0 \mathrm{~Hz})$, and proton at7.38( $\mathrm{d}, \mathrm{j}=8.0 \mathrm{~Hz}), 7.98(\mathrm{dd}, \mathrm{j}=8.0,2.4$ $\mathrm{Hz}$ ) and $8.08(\mathrm{~d}, \mathrm{j}=2.4 \mathrm{~Hz})$ respectively . the $\mathrm{mg}$ stearate represent in chemical shift at ppm $0.88(\mathrm{t}, \mathrm{J}=8.0 \mathrm{~Hz}), 1.26(\mathrm{~S}), 1.58(\mathrm{q}, \mathrm{J}=7.1 \mathrm{~Hz})$, and $2.38(t, J=7.1 \mathrm{~Hz})$. The (Figures 8 and 9) shows he chemical shift for sildenafil peaks and other excipient (Figure 10).

Additionally, the experiment shows a variation of genuine and counterfeit Viagra. For the consumer, the box of the counterfeit formulation is "authenticated "by the Pfizer logo. The blister is very similar to the genuine one and the tablets are identical, the box of counterfeiting formulation of Cialis is the same. The Figure 11 below show slightly different between genuine Viagra and substandard one, which the counterfeited lack the API peak in $3.6 \mathrm{ppm}$ chemical shifts marked in rectangle shape and between $3.2 \mathrm{ppm}$ and $3.4 \mathrm{ppm}$.the variation of molar ratio between the API and Mg Stearate as excipients in the genuine and fake one was observed in oval shape which that confirm the low quality of the samples tested (Table 6).

In contrast, the genuine Cialis formulation represent the API peaks at $6.65(\mathrm{~d}, \mathrm{j}=8.0 \mathrm{~Hz}), 6.80(\mathrm{dd}, \mathrm{j}=8.0,1.4 \mathrm{~Hz}), 7.02(\mathrm{~m}, 7.10(\mathrm{~m}$,
7.25( $d, j=7.9 \mathrm{~Hz})$ and $7.50(d, j=7.9 \mathrm{~Hz})$, while these peak positions in the fake formulation of Cialis and Snafi were not observed (Figure 12).

NMR is a great tool for studying such formulations, Nevertheless, the use of other solvents such as $\mathrm{D}_{2} \mathrm{O}$ and $\mathrm{CD}_{3} \mathrm{CN}$ might be preferred to investigate other core excipients for Viagra, Cialis, and Snafi formulations. DOSY NMR is a powerful analytical method which allows the finger printing of pharmaceutical formulations and can be used to determine the similarities or differences between samples. Not only can it distinguish between genuine and counterfeit tablets, but it is also helpful in determining the relationships between different samples and thus assists in the investigation of the sources of these drugs, so DOSY NMR might be preferred to use in this experiments to produces valuable investigations for tested formulations. Screening between imitation and authentic Viagra was also described using NIR spectroscopy combined with wavelength correlation and principal component analysis [15] also, Raman spectroscopy is more informative, as the excipients microcrystalline cellulose, magnesium stearate ,lactose, and sucrose can be detected [17] The best methods for identification and quantification of active pharmaceutical ingredients are chromatographic ones [2-8]; however, they do not provide any information on excipients. Finally, NMR is an ideal technique for quality assessment of API and excipients, even for both identification and quantification of single medicines and complex herbal mixture. Other complementary techniques are needed for identification such as HPLC, near infra-red (NIR) or Liquid Chromatography-Mass Spectrometry (Figures 13-15). 


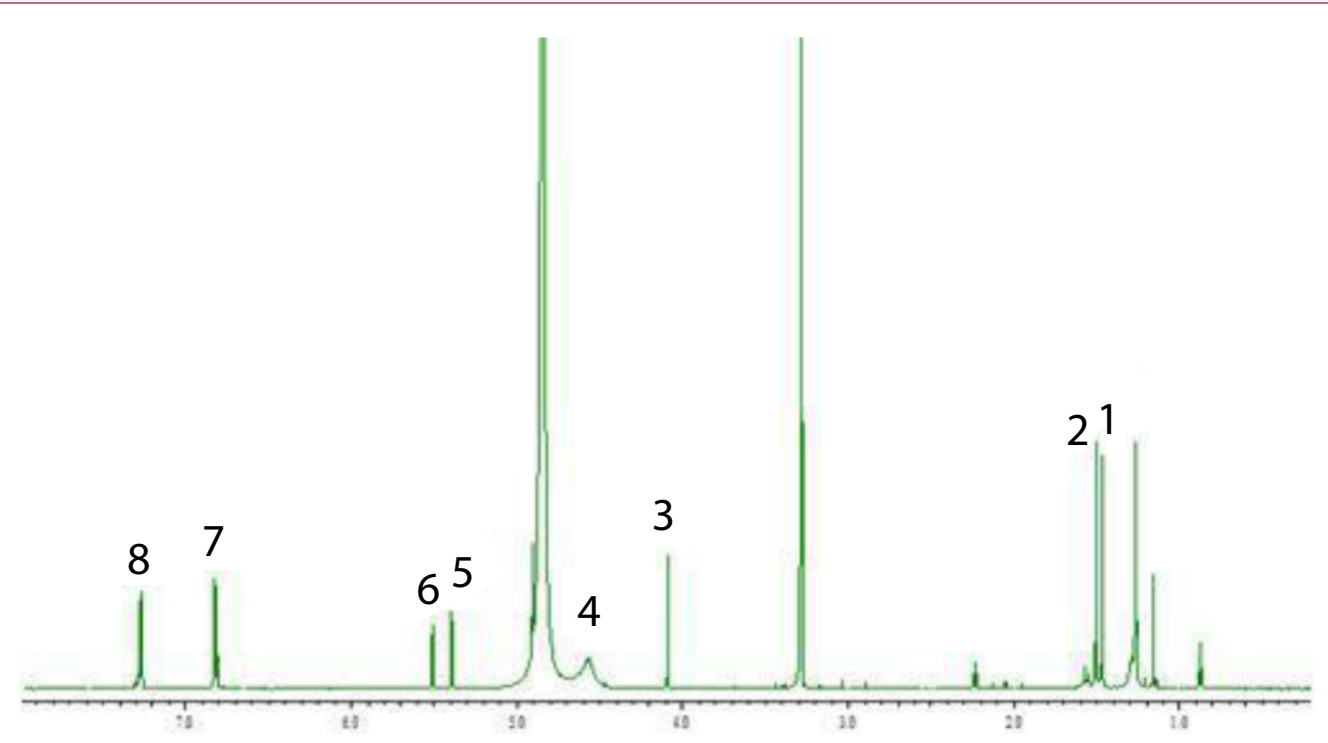

Figure 8 Amoxicillin sample spectra chemical shift (ppm).

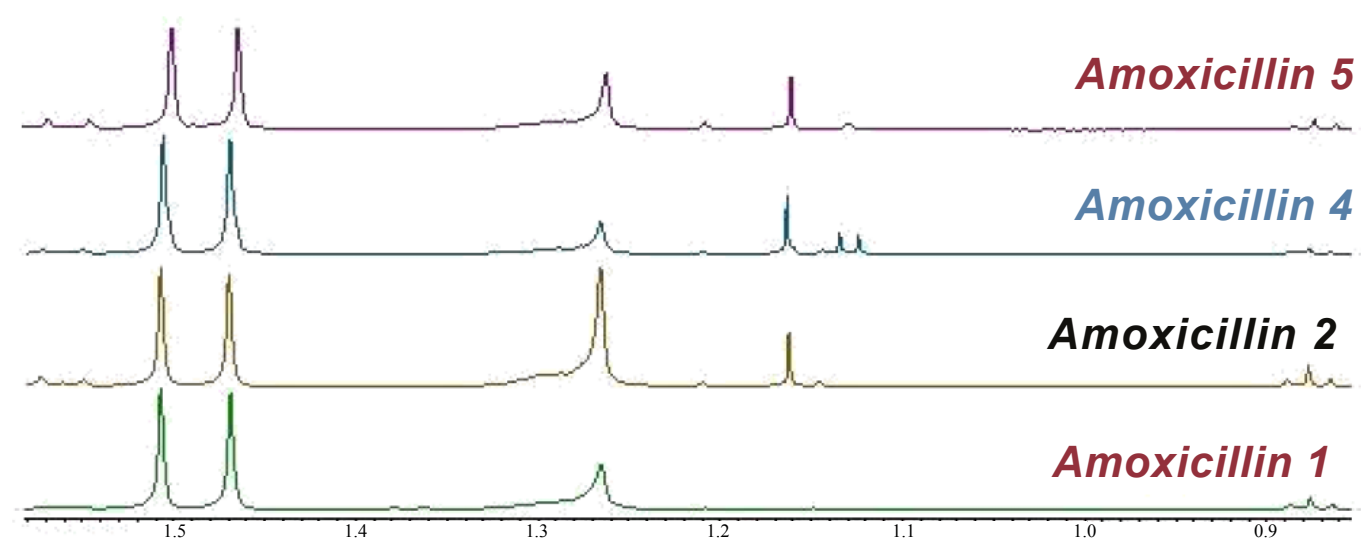

Figure 9 Amoxicillin overlay spectra.<smiles>CCCc1nn(C)c2c(=O)nc(-c3cc(S(=O)(=O)N4CCN(C)CC4)ccc3OCC)[nH]c12</smiles>

Sildenafil

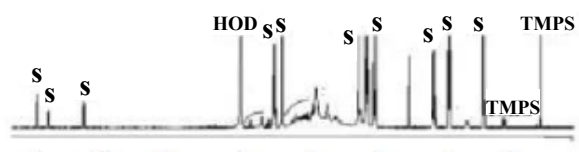

Figure 10 Peaks of Sildenafil. 


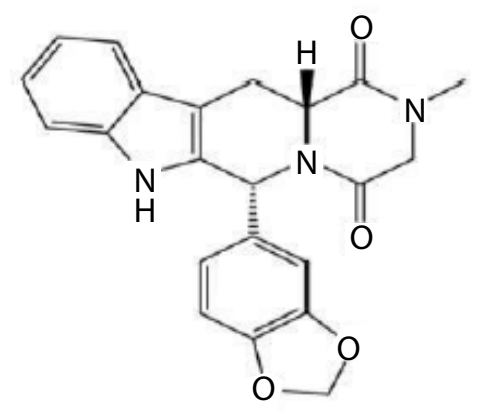

Tadalafil

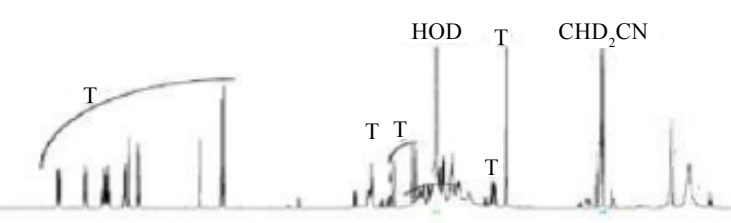

Figure 11 Peaks of Tadalafil.

Table 6 Area under the peak of Amoxicillin samples.

\begin{tabular}{|c|c|c|c|c|}
\hline 8.09 & $1 \mathrm{H}, \mathrm{d}(2.4)$ & & 7.57 & $1 \mathrm{H}, \mathrm{d}(7.9)$ \\
\hline 7.94 & $1 \mathrm{H}, \mathrm{dd}(8.7)$ & & 7.3 & $1 \mathrm{H}, \mathrm{d}(7.9)$ \\
\hline 7.35 & $1 \mathrm{H}, \mathrm{d}(8.7)$ & & 7.09 & $1 \mathrm{H}, \mathrm{m}$ \\
\hline 4.29 & $2 \mathrm{H}, \mathrm{q}(6.8)$ & & 7.07 & $1 \mathrm{H}, \mathrm{m}$ \\
\hline 4.18 & $3 \mathrm{H}, \mathrm{S}$ & & 6.89 & $1 \mathrm{H}, \mathrm{dd}(8.09)$ \\
\hline 3.94 & $4 \mathrm{H}, 2$ broad s & & 6.85 & $1 \mathrm{H}, \mathrm{d}(1.4)$ \\
\hline 2.82 & $2 \mathrm{H}, \mathrm{t}(7.4)$ & & 6.74 & $1 \mathrm{H}, \mathrm{d}(8.0)$ \\
\hline 3.62 & $2 \mathrm{H}, \mathrm{I}$ broad s & & 6.12 & $1 \mathrm{H}, \mathrm{s}$ \\
\hline 2.92 & $3 \mathrm{H}, \mathrm{s}$ & & 5.89 & $1 \mathrm{H}, \mathrm{d}(1.0)$ \\
\hline 1.73 & $2 \mathrm{H}, \operatorname{sect}(7.4)$ & & 5.88 & $1 \mathrm{H}, \mathrm{d}(1.0)$ \\
\hline 1.46 & $3 \mathrm{H}, \mathrm{t}(7.0)$ & & 4.37 & $1 \mathrm{H}, \mathrm{dd}(11.6)$ \\
\hline \multirow[t]{5}{*}{0.93} & $3 \mathrm{H}, \mathrm{t}(7.4)$ & 1 & 4.14 & $1 \mathrm{H}, \mathrm{dd}(17.6)$ \\
\hline & & & 3.9 & $1 \mathrm{H}, \mathrm{d}(17.6)$ \\
\hline & & & 3.6 & $1 \mathrm{H}, \mathrm{dd}(15.7)$ \\
\hline & & & 3.11 & $1 \mathrm{H}, \mathrm{ddd}(16.1)$ \\
\hline & & & 2.97 & $3 \mathrm{H}, \mathrm{s}$ \\
\hline
\end{tabular}

\section{A) Data measured in $D_{2} O$; B) Data measured in $\left(C D_{3} C N: D_{2} 0,80: 20\right)$.}

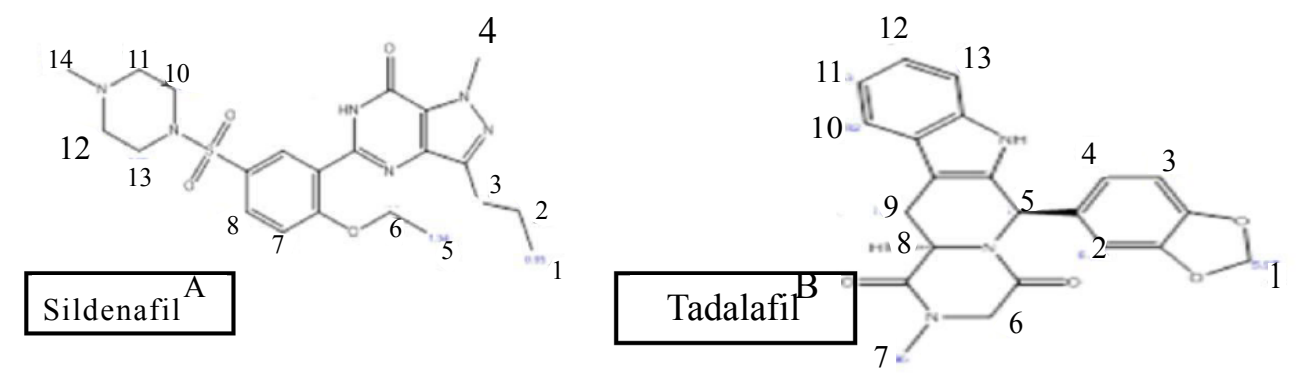

Figure 12 Chemical structure of Sildenafil and Tadalafil. 


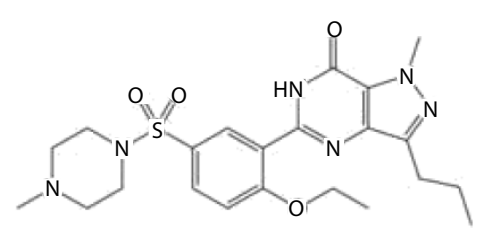

Sildenafil

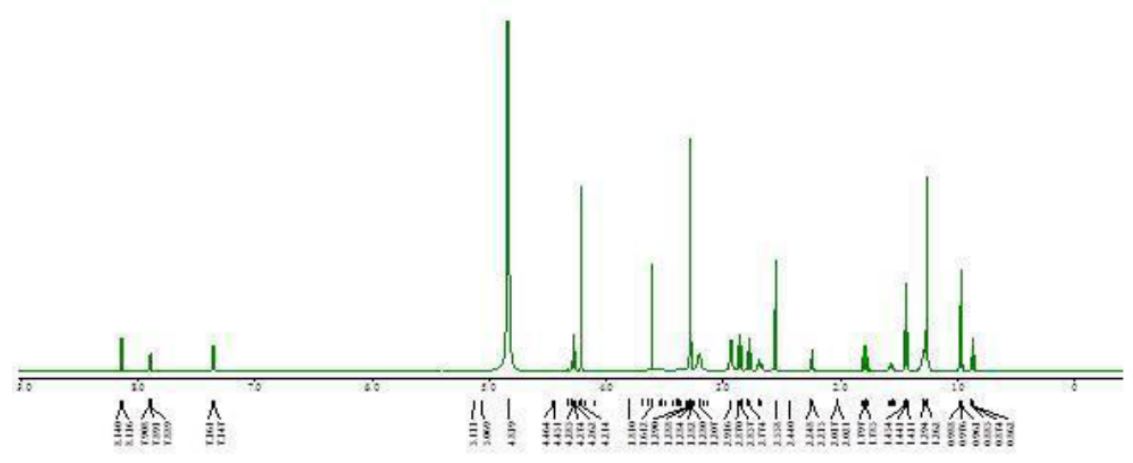

Figure 13 H NMR spectra of Sildenafil (Viagra) .

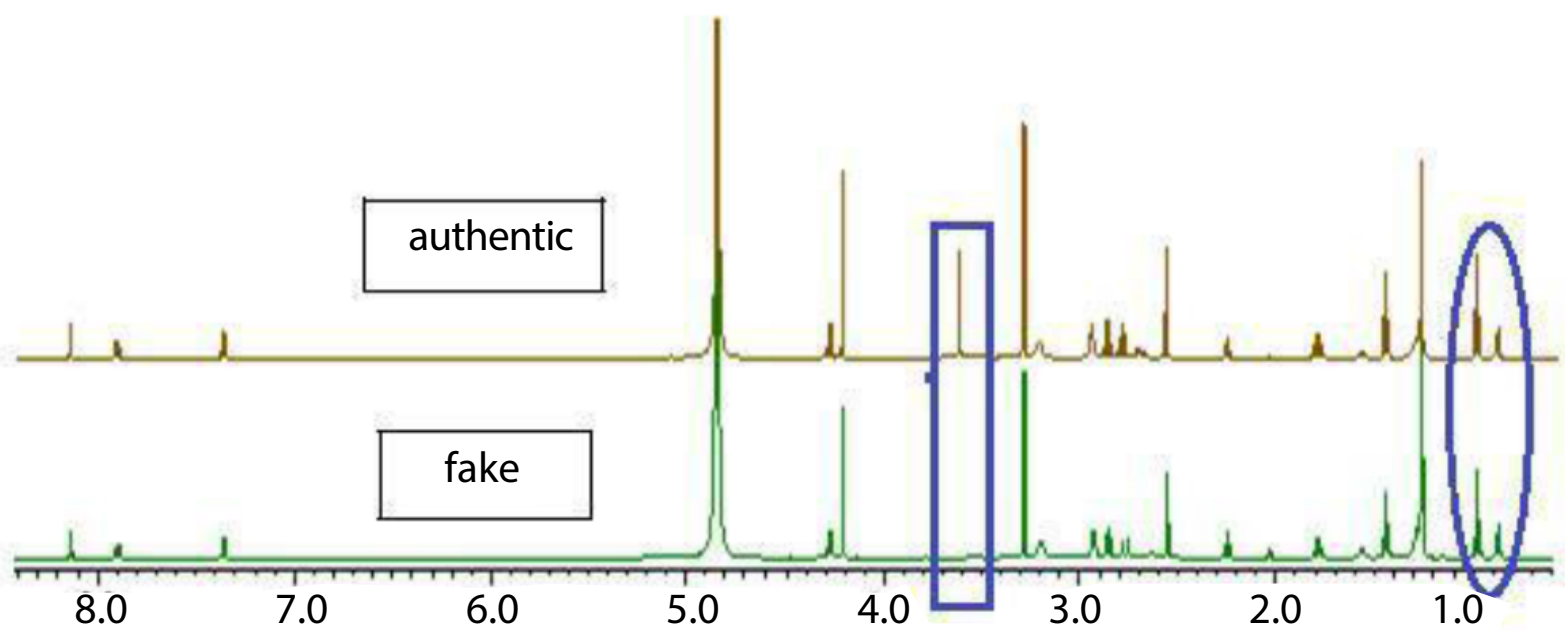

Figure 14 Overlay of ${ }^{1} \mathrm{H} 1 \mathrm{D}$ NMR spectra of fake and authentic Sildenafil in $\mathrm{CD}_{3} \mathrm{OD}$ at $25^{\circ} \mathrm{C}$.

hll
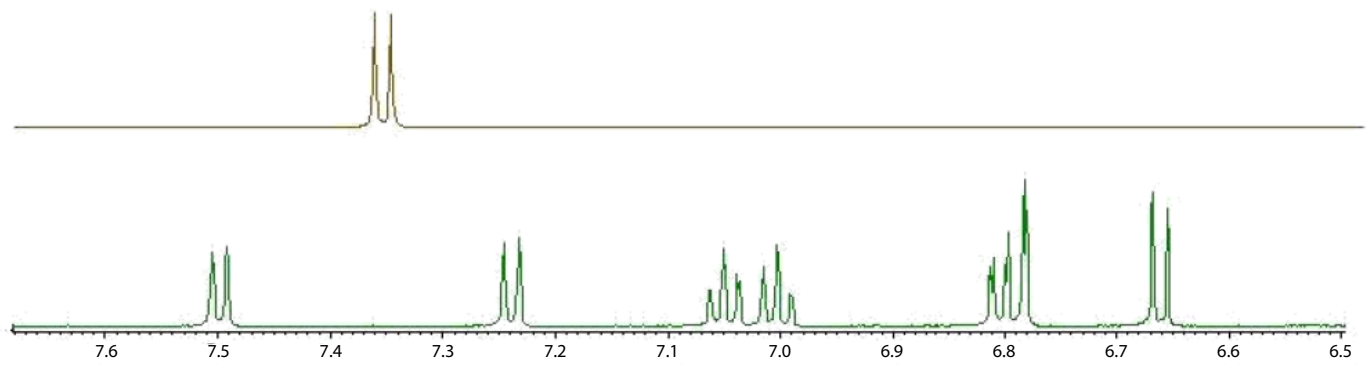

Figure 15 The genuine Cialis formulation represent the API peaks at 6.65 . 


\section{References}

1 Abdullahi AA, Van Zyl-Schalekamp C, Seneka A (2014) Perceived Threat of Malaria and the Use of Insecticide Treated Bed Nets in Nigeria. African Sociological Review 17: 25-44.

2 Afnan A (2010) Defining of Pharmaceutical Quality. Pharma QBD

3 Al-Arifi MN, Al-Dhuwaili AA, Gubara OA, Al-Omar HA, Al-Sultan MS, et al. (2007). Pharmacists' understanding and attitudes towards pharmaceutical care in Saudi Arabia. Saudi Pharmaceutical Journal 15: 146 .

4 Al-Ghamdi MS (2001) Empirical treatment of uncomplicated urinary tract infection by community pharmacist in the Eastern province of Saudi Arabia. Saudi Medical Journal 22: 1105-1108.

5 Al Hakim AH (2013) Inspection tours in saudi arabia by SFDA.

6 Almalki M, Fitzgerald G, Clark M (2011) Health care system in Saud Arabia: an overview. East Mediterr Health J 17: 784-793.

7 Alshammasi A (1990) The pharmacy profession in Saudi Arabia. Saudi Medical Journal 11: 427-431.

8 Armstrong E, Bootman J, Al-Dhewalia H (1992) Pharmacy practice in eastern Saudi Arabia. American journal of hospital pharmacy 49: 2252-2254.

9 Arts D (2002) Defining and improving data quality in medical registries: a literature review, case study, and generic framework. J Am Med Inform Assoc 9: 600-611.

10 http://www.asq.org/glossary/q.html, retrieved 2008-07-20.

11 Ball D, Al-Othman F (2007) Drug information resources at private community pharmacies in Kuwait. Medical principles and practice: international journal of the Kuwait University 16: 107.

12 Bate R, Coticelli P, Tren R, Attaran A (2008) Antimalarial drug quality in the most severely malarious parts of Africa-a six country study. PLoS One 3: 2132.

13 Bate R, Hess K (2010) Assessing website pharmacy drug quality: safer than you think? PLoS One 5: 12199.

14 Bate R, Jensen P, Hess K, Mooney L, Milligan J (2013) Substandard and falsified anti-tuberculosis drugs: a preliminary field analysis. Int J Tuberc Lung Dis 17: 308-311.

15 Behrens R, Awad A, Taylor R (2002) Substandard and counterfeit drugs in developing countries. Trop Doct 32: 1-2.

16 http://www.businessdictionary.com/definition/quality.html.

17 Burns DA, Ciurczak EW (2007). Handbook of near-infrared analysis, ( $\left.3^{\text {rd }} \mathrm{Edn}\right), \mathrm{CRC}$ press: USA.

18 Caudron JM, Ford N, Henkens M, Mace C, Kiddle-Monroe R, et al. (2008) Substandard medicines in resource-poor settings: a problem that can no longer be ignored. Trop Med Int Health 13: 1062-1072.

$19 \mathrm{http}: / /$ www.cdc.gov/getsmart/antibiotic-use/anitbiotic-resistancefaqs.html\#e.

20 Derendorf H (1995) Drug Actions: Basic Principles and Theraputic Aspects, CRC press: USA.

21 Doblhoff-Dier O, Bliem R (1999) Quality control and assurance from the development to the production of biopharmaceuticals. Trends Biotechnol 17: 266-270.

22 https://ww w.fda.gov/downloads/Drugs/ GuidanceComplianceRegulatoryInformation/Guidances/ UCM469119.pdf
23 Fernandez FM, Hostetler D, Powell K, Kaur H, Green MD, et al. (2011) Poor quality drugs: grand challenges in high throughput detection, countrywide sampling, and forensics in developing countries. Analyst 136: 3073-3082.

24 www.alpencapital.com/media-reports-2013.

25 http://crofsblogs.typepad.com/h5n1/2014/05/antibiotic-resistantbugs-need-global-response-say-health-experts.html.

26 Hämmerlein A, Griese N, Schulz M (2007) Survey of drug-related problems identified by community pharmacies. Ann Pharmacother 41: 1825-1832.

27 Holzgrabe U, Deubner R, Schollmayer C, Waibel B (2005) Quantitative NMR spectroscopy - Applications in drug analysis. J Pharm Biomed Anal 38: 806-812.

28 Johnston A, Holt D (2013) Substandard drugs: a potential crisis for public health. Br J Clin Pharmacol 78: 218-243.

29 Kasal A, Budesinsky M, Griffiths, WJ (2010) Spectroscopic methods of steroid analysis Steroid Analysis. Springer 27-161.

30 Kelesidis T, Kelesidis I, Rafailidis PI, Falagas ME (2007) Counterfeit or substandard antimicrobial drugs: a review of the scientific evidence. J Antimicrob Chemother 60: 214-236.

31 Keoluangkhot V, Green MD, Nyadong L, Fernández FM, Mayxay M, et al. (2008). Impaired clinical response in a patient with uncomplicated falciparum malaria who received poor-quality and underdosed intramuscular artemether. Am J Trop Med Hyg 78: 552-555.

32 Khojah HM, Pallos H, Yoshida N, Akazawa M, Tsuboi H, et al. (2013) The Quality of Medicines in Community Pharmacies in Riyadh, Saudi Arabia: A Lot Quality Assurance Sampling (LQAS)-Based Survey. Pharmacology \& Pharmacy 4: 511.

33 Kyriacos S, Mroueh M, Chahine R, Khouzam O (2008) Quality of amoxicillin formulations in some Arab countries. J Clin Pharm Ther 33: 375-379.

34 The Lancet (2013) Strengthening global action against poor quality drugs. The Lancet 381: 599.

35 h t t p:// w w w. sciencedirect.com/science/ journal/01406736/376/9754?sdc=1

36 Siva N (2010) Tackling the booming trade in counterfeit drugs. The Lancet 376: 1725-1726.

$37 \mathrm{http}: / / g u l f n e w s . c o m / n e w s / g u l f / u a e / g e n e r a l / f a k e-s e x-s t i m u l a n t s-$ and-sedatives-worth-dh20m-seized-in-jebel-ali-raid-1.200589.

38 Lexchin J, Bero LA, Djulbegovic B, Clark O (2003) Pharmaceutical industry sponsorship and research outcome and quality: systematic review. BMJ 326: 1167-1170.

39 Lybecker KM (2004) Economics of reimportation and risks of counterfeit pharmaceuticals. Manag Care 13: 10-13.

40 ht t p://ww w.m hra.gov.uk/Safetyinformation/ Safetywarningsalertsandrecalls/DrugAlerts/ind ex.htm.

41 Mostafa A (2014) poor quality medicines found in riyadh. alqabas 11.

42 Newton PN, Green MD, Fernández FM (2010) Impact of poor-quality medicines in the developing' world. Trends Pharmacol Sci 31: 99-101.

43 Newton PN, Green MD, Fernández FM, Day NPJ, White NJ (2006) Counterfeit anti-infective drugs. Lancet Infect Dis 6: 602-613.

44 Newton PN, Lee SJ, Goodman C, Fernández FM, Yeung S, et al. (2009) Guidelines for field surveys of the quality of medicines: a proposal. PLoS Med 6: e1000052. 
45 Pharma ( 2010) Definition and classification of Drug or Pharmaceutical Regulatory Aspects of drugs approval. Pharmacist Pharma Journal.

46 Philip B (1979) Quality is Free. McGraw-Hill, New York.

47 Pickard AL (2002) Guide to good manufacturing practice for medicinal products.

48 Carpenter PJ, McGinnis M (2006) Matrix of drug quality reports in USAID-assisted countries. Paper presented at the Rockville, The United States Pharmacopeial Convention, USA.

49 http://psnc.org.uk/psncs-work/about-community-pharmacy/.

50 Ratanawijitrasin S, Wondemagegnehu E (2002) Effective drug regulation: A multicountry study: World Health Organization Geneva, Switzerland

51 http://en.starafrica.com/news/sleone-warns-over-substandardghanaian-drugs.html.

52 Said MM, Gibbons S, Moffat AC, Zloh M (2011) Near-infrared spectroscopy (NIRS) and chemometric analysis of Malaysian and UK paracetamol tablets: A spectral database study. Int J Pharm 415: 102-109.

53 Seear M, Gandhi D, Carr R, Dayal A, Raghavan D, et al. (2011) The need for better data about counterfeit drugs in developing countries: a proposed standard research methodology tested in Chennai, India. J Clin Pharm Ther 36: 488-495.

54 Senior K (2008) Global health-care implications of substandard medicines. Lancet Infect Dis 8: 666.

55 http://old.sfda.gov.sa/En/Home/Topics/about/. SFDA. regulations and guidelines of Saudi food drug authority.

56 www.old.sfda.gov.sa/en/drug/topic/10-01-2007.

57 http://www.sfda.gov.sa/en/news/Pages/homenews31-10-2011-a6. aspx.

58 Taylor RB, Shakoor O, Behrens RH (1995) Drug quality, a contributor to drug resistance. The Lancet 346: 122.
59 Taylor RB, Shakoor O, Behrens RH, Everard M, Low AS, et al. (2001) Pharmacopoeial quality of drugs supplied by Nigerian pharmacies. The Lancet 357: 1933-1936.

60 Trefi S, Gilard V, Balayssac S, Malet-Martino M, Martino R (2009) The usefulness of 2D DOSY and 3D DOSY-COSY $1 \mathrm{H}$ NMR for mixture analysis: application to genuine and fake formulations of sildenafil (Viagra). Magn Reson Chem 47: 163-173.

61 www.aei/files/2012/02/00/appendix.

62 http://www.asrames.org/wp-content/uploads/2016/07/ Ensuring-Quality-of-Medicines-in-Resource-Limited-Countries-AnOperationalGuide.pdf

63 http://apps.who.int/medicinedocs/en/d/Js6169e/.

64 http://www.emro.who.int/emrinfo/index.asp?Ctry=saa

65 http:// www. who.int/media_centre/fact_sheets/fs_20050506.

66 http://www.who.int/medicines/services/counterfeit/impact/ TheNewEstimatesCounterfeit.p df.

67 WHO (2007). Quality assurance of pharmaceuticals: a compendium of guidelines and related materials. Good manufacturing practices and inspection 2 .

68 http://www.who.int/mediacentre/factsheets/fs275/en/index.html.

69 http://www.emro.who.int/health-topics/pharmaceutical-products/ index.html

70 www.whpa.org/background_medicines_counterfeiting_in_africa_ chioma_jo_onwuka11-2010.pdF.

71 Wiecek A, Mikhail A (2006) European regulatory guidelines for biosimilars. Nephrology Dialysis Transplantation, 21: 17-20.

72 ondemagegnehu E (1999) Counterfeit and substandard drugs in Myanmar and Viet Nam. World Health Organization, Geneva: Switzerland. 